\title{
MULTI-SOURCE CAPACITATED LOT SIZING FOR ECONOMICALLY VIABLE AND CLEAN BIOFUEL PRODUCTION
}

\author{
A Thesis by \\ Alperen Burak Kantas \\ Bachelor of Science, Kadir Has University, 2012
}

Submitted to the Department of Industrial and Manufacturing Engineering and the faculty of the Graduate School of

Wichita State University

in partial fulfillment of

the requirements for the degree of

Master of Science in Industrial Engineering

December 2014 
(C) Copyright 2014 by Alperen Burak Kantas

All Rights Reserved 


\section{MULTI-SOURCE CAPACITATED LOT SIZING FOR ECONOMICALLY VIABLE AND CLEAN BIOFUEL PRODUCTION}

The following faculty members have examined the final copy of this thesis for form and content, and recommend that it be accepted in partial fulfillment of the requirement for the degree of Master of Science with a major in Industrial Engineering.

İ. Esra Büyüktahtakın, Committee Chair

Janet Twomey, Committee Member

Bayram Yildirim, Committee Member

Ramazan Asmatulu, Committee Member 


\section{DEDICATION}

To my parents, my brother, and my dear friends 


\section{ACKNOWLEDGMENTS}

I would like to thank my adviser, İ. Esra Büyüktahtakın, for her many years of thoughtful and patient guidance and support. Thanks are also due to Halil Ibrahim Cobuloğlu. I deeply appreciate their friendship and role modeling that have highly contributed to my professional development. I would also like to extend my gratitude to members of my committee, Janet Twomey, Mehmet Bayram Yildirim, and Ramazan Asmatulu, for their helpful comments and suggestions on all stages of this project. 


\begin{abstract}
Excessive water usage and $\mathrm{CO}_{2}$ emissions resulting from industrial systems and processes have significantly raised environmental concerns. The primary sources of $\mathrm{CO}_{2}$ emissions are production and transportation, while the biofuel industry itself consumes a considerable amount of water in the U.S. In this paper, a mixed-integer linear programming (MILP) capacitated lot-sizing model for analyzing the economic and environmental feasibility of ethanol production using multiple biomass sources is developed. The model minimizes the cost of ethanol production while considering its possible adverse environmental impacts such as $\mathrm{CO}_{2}$ emissions and excessive water usage during ethanol production. The overall cost of ethanol production includes production, setup, and inventory holding costs with penalties for environmental impacts, along with income from ethanol tax credits and electricity generated from waste heat. A sensitivity analysis is performed and results are analyzed in order to improve an understanding of the economic viability of ethanol production and associated environmental effects. Results show that switchgrass is the most profitable and preferred biomass type when there is an unlimited supply of all biomass sources, while wheat and corn become more preferable in the case of a limited biomass supply. Compared to low- and medium-demand cases, when there is high demand, total costs increase significantly due to multiple production setup costs, excessive water usage, and $\mathrm{CO}_{2}$ emissions under limited biomass supply. The solution of the proposed model also indicates that if ongoing technology investments in the conversion rate succeed, the total cost of ethanol production can decrease by 21 percent. Finally, results show that the proposed MILP model provides valuable insights and strategies for future investors, decision-makers, and the government on both economic and environmental impacts of biofuel production using various biomass types.
\end{abstract}




\section{TABLE OF CONTENTS}

Chapter

Page

1. INTRODUCTION 1

2. PROBLEM STATEMENT $\quad 6$

$\begin{array}{ll}\text { 3. } & 7\end{array}$

3.1 Objective Function 7

$\begin{array}{ll}3.2 & \text { Production and Capacity Constraints }\end{array}$

3.3 Environmental Constraints $\quad 8$

3.4 Bounds on Variables $\quad 8$

4. CASE STUDY DATA AND INPUT PARAMETERS 9

4.1 Production Cost 9

4.1.1 Variable Production Cost 9

4.1.2 Fixed Production Cost 9

4.2 Inventory Holding Cost 10

4.3 Feedstock Purchasing Cost 10

4.4 Feedstock Conversion Factors $\quad 10$

4.5 Electricity Production $\quad 11$

4.6 Water Usage 11

$4.7 \mathrm{CO}_{2}$ Emissions $\quad 11$

$4.8 \quad \mathrm{CO}_{2}$ Tax 12

4.9 Water Usage Penalty 12

4.10 Demand and Capacity 12

$\begin{array}{ll}4.10 .1 \quad \text { Demand } & 12\end{array}$

$\begin{array}{ll}\text { 4.10.2 Biomass Availability } & 12\end{array}$

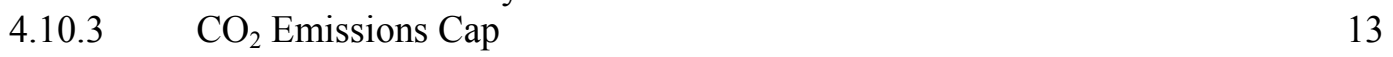

$\begin{array}{ll}4.10 .4 & 13\end{array}$

5. COMPUTATIONAL RESULTS 14

5.1 Impact of Demand on Results $\quad 19$

5.2 Impact of Biomass Availability on Results 21

5.3 Impact of $\mathrm{CO}_{2}$ Cap on Results 25

5.4 Impact of Water Usage Cap on Results 25

5.5 Impact of Technology Improvement on Results 26

6. CONCLUDING REMARKS AND FUTURE DIRECTIONS 28

$\begin{array}{ll}\text { BIBLIOGRAPHY } & 31\end{array}$ 


\section{LIST OF TABLES}

Table

Page

1. Variable and Fixed Production Cost Data 9

2. Feedstock Purchasing Cost and Biofuel Conversion Factors 10

3. Water Usage and $\mathrm{CO}_{2}$ Emissions Released 11

4. Computational Results for Different Experimental Designs 15 


\section{LIST OF FIGURES}

Figure

1. Profitability of biomass production 16

2. Cost breakdown of annual ethanol production 17

3. Breakdown of total used biomass (a) and breakdown of total produced ethanol (b) 17

4. Breakdown of total $\mathrm{CO}_{2}$ emissions (a) and breakdown of total water usage (b) 18

5. Ethanol production timeline including used amounts of biomass and inventory held in base case

6. Breakdown of total ethanol production for low-demand case (a) and breakdown of total production cost for low-demand case (b)

7. Breakdown of total ethanol production for high-demand case (a) and breakdown of total production cost for high-demand case (b)

8. Breakdown of total production cost for unlimited biomass availablity case

9. Breakdown of total ethanol production for low-biomass availability case (a) and breakdown of total production cost for low-biomass availability case (b)

10. Breakdown of total ethanol production for high-biomass availability case (a) and breakdown of total production cost for high-biomass availability case (b)

11. Cumulative emissions released for only one type of biomass production during each production period

12. Breakdown of total production cost for low- $\mathrm{CO}_{2}$ emissions cap case (a) and high $\mathrm{CO}_{2}$ emissions cap (b)

13. Impact of $\mathrm{CO} 2$ tax penalty on biomass preferences

14. Computational results of technology improvement 


\section{NOMENCLATURE}

\section{Indices}

$b_{i t} \quad$ Amount of biomass type $i$ available for purchase in period $t$ (ton)

$c_{t} \quad \mathrm{CO}_{2}$ emissions cap at period $t(\mathrm{~kg})$

$d_{t} \quad$ Total ethanol demand in period $t$ (gallon)

$e_{i} \quad$ Biomass-to-ethanol conversion factor for biomass type $i$ (gallon/ton)

$f_{i t} \quad$ Fixed cost of ethanol production from biomass type $i$ in period $t(\$)$

$h_{t} \quad$ Ethanol inventory holding cost at period $t$ (\$/gallon)

$i \quad$ Biomass type

I Set of biomass types

$I_{t} \quad$ Ethanol inventory carried at the end of period $t$ (gallon)

$k \quad$ Electricity credit per each gallon of biofuel produced (\$/gallon)

$M_{i t} \quad$ Amount of biomass type $i$ used in period $t$ (ton)

$p_{i t} \quad$ Variable cost of ethanol production from biomass type $i$ in period $t$ (\$/gallon)

$\hat{p}_{\mathrm{it}} \quad \mathrm{CO}_{2}$ emissions occurring per one gallon of ethanol production from biomass type $i$ in period $t$ ( $\mathrm{kg} /$ gallon)

$q_{t} \quad$ Production capacity in period $t$ (gallon)

$r_{i} \quad$ Biomass purchasing cost for biomass type $i(\$ /$ ton $)$

$S_{t} \quad$ Water usage exceeding predefined water usage cap in period $t$ (gallon)

$t \quad$ Time period

$T \quad$ Set of time periods in modeling horizon

$U_{t} \quad \mathrm{CO}_{2}$ emissions exceeding predefined emission cap in period $t(\mathrm{~kg})$

$v \quad$ Credit for producing ethanol (\$/gallon)

$w_{i t} \quad$ Water usage for ethanol production from biomass type $i$ in period $t$ (gallon/gallon)

$X_{i t} \quad$ Production amount of ethanol from biomass type $i$ in period $t$ (gallon)

$Y_{i t} \quad 1$ if there is production from biomass type $i$ in period $t$; otherwise, 0 . 


\section{NOMENCLATURE (continued)}

$z \quad$ Penalty for $\mathrm{CO}_{2}$ emissions exceeding emissions cap $(\$ / \mathrm{kg})$

$\mu \quad$ Penalty for water usage exceeding water-usage cap (\$/gallon)

$\Omega_{t} \quad$ Water usage cap at period $t$ (gallon) 


\section{CHAPTER 1}

\section{INTRODUCTION}

Increased consumption of fossil fuels and high greenhouse gas emissions have necessitated the utilization of environment-friendly energy sources. Biofuel, one of the most efficient renewable energy sources (European Renewable Energy Council, 2008), can reduce some undesirable effects of fossil fuels, such as excessive $\mathrm{CO}_{2}$ emissions and dependence on unstable foreign supplies (United States Environmental Protection Agency, 2014). In 2010, worldwide biofuel production reached 28 billion gallons and took a 17 percent share among all other fuels produced (Worldwatch Institute, 2013).

Currently, biofuel production is dominated by food crops, including corn, wheat, soybeans, and sugarcane. However, to avoid possible undesirable impacts on the safety of food resources and prevent excessive $\mathrm{CO}_{2}$ emissions, researchers have focused on developing alternative biofuel sources, called cellulosic biomass (Akgul et al., 2012). Non-food biomass sources such as bio-waste and grasses are used to derive cellulosic biomass. These sources have less impact on food supplies and lead to fewer $\mathrm{CO}_{2}$ emissions (Shalaby, 2013).

Although biofuel is one of the cleanest sources of energy, its economic viability is a major concern (Gonela \& Zhang, 2014). In order to assess the economic feasibility of biofuel production, related costs must be taken into account. In particular, ethanol production has two main production costs: fixed and variable (Bain, 2007). Furthermore, costs associated with holding ethanol inventory to meet future demand should also be considered.

In addition to the economic cost of biofuels, related environmental impacts should also be taken into consideration in order to ensure the sustainability of biofuel production. For example, leaving a carbon footprint is a major concern in ethanol production, as is the case for any other industrial and manufacturing processes. Čuček et al. (2012) note that biomass energy releases a lower carbon footprint compared to fossil fuels. On the other hand, Hammond and Seth (2013) find that the carbon footprint is high for first-generation (food-based) biofuels, while the use of second-generation (cellulosic) biofuels 
could contribute significantly to reducing the carbon footprint. In the optimization model in this thesis, a carbon cap is imposed and penalty costs regarding excessive carbon emissions are considered in order to reflect environmental costs associated with the carbon footprint.

In addition to the carbon footprint of biofuel production, its water footprint is also a big concern. Čuček et al. (2012) define the water footprint as the total volume of direct and indirect fresh water used, consumed, and polluted. For example, a driven car would require 50 gallons of water per mile, considering the total amount of water needed for irrigation of the biomass and its subsequent processing into ethanol (Dominguez-Faus et al., 2009). The increasing demand for biofuels will adversely impact fresh water supplies further unless sustainable biofuel production policies are developed and implemented. Similar to the carbon footprint case, this study focuses on developing optimal biofuel production plans while imposing a cap on the amount of water consumed to produce biofuels during ethanol processing and a penalty for related excessive water consumption.

In the literature, a significant number of studies focus on the ethanol supply chain and corresponding economic costs, while fewer studies focus on ethanol production planning and scheduling. Xie et al. (2014) propose a multi-stage mixed-integer linear programming (MILP) model to minimize the total cost of the biofuel supply chain, feedstock harvesting, and transportation. Marvin et al. (2012) propose an MILP model for optimizing the biomass-to-ethanol supply chain to determine optimal locations and capacities of biorefineries while considering harvesting and distribution of feedstocks. Da Silva et al. (2013) develop a multi-choice mixed-integer goal programming model for optimizing the production planning of an ethanol company. Their model considers traditional collection and process methodologies for the design of lots, representing the production cycle among sugar, alcohol, molasses, and derivatives. In another study, Corsano et al. (2013) present an MILP model for optimizing the design of an ethanol supply chain and production scheduling by considering raw material sites, production facilities, and end-users.

Apart from studies on economic evaluation, there are also a large number of ethanol supply chain optimization papers, including those on associated environmental impacts, but relatively few of them 
focus on ethanol production planning optimization. Cobuloglu and Büyüktahtakın (2014) provide a multiobjective MILP for maximizing the revenue from harvested switchgrass biomass and its environmental benefits in the state of Kansas. They implement a sensitivity analysis for addressing uncertainty in the budget and productivity, and provide insights into the economic and environmental impacts of switchgrass production. Bernardi et al. (2012) present a model to address sustainable transportation systems in a biofuel supply chain while accounting for both environmental and economic variables. Corsano et al. (2011) propose a mixed-integer non-linear programming model for improving the efficiency of a sugar-based biofuel supply chain. They include residue recycling in their model in order to reduce the environmental impact caused by disposal during biofuel production. Huang et al. (2010) develop a multi-stage MILP model for planning a biofuel production supply chain system. They minimize the total cost of this system, from biowaste feedstock fields to end-users, while satisfying demand with limited resources. Gonela and Zhang (2014) focus on industrial symbiosis for evaluating concerns of the economical infeasibility of biofuel production. Their model collates separate ways of efficiently utilizing resources, reducing waste, and increasing profits. Tan et al. (2009) presents a fuzzy multi-objective modeling approach to determine an optimal bioenergy system configuration based on three footprint metrics: land use, water, and carbon. Their model is implemented to analyze different scenarios for integrated production of biodiesel, biofuel, and electricity. Ren et al. (2013) develop a model for designing the most sustainable biofuel supply chain by minimizing the total ecological footprint while considering the possibility of multiple feedstocks, transportation modes, alternative technologies, transportation patterns, and waste disposal methods.

MILP approaches have been widely used for modeling and solving production planning problems. For example, Hartman et al. (2010) propose new integer programming-based algorithms for the capacitated lot-sizing problem by generating valid inequalities via dynamic programming. On the other hand, a few studies focus on the environmental impacts of the general production and inventory planning processes. Benjaafar et al. (2013) demonstrate how $\mathrm{CO}_{2}$ emission concerns can be incorporated into an MILP model that includes production, procurement, and inventory-management decisions. They 
provide insight into the impact of operational decisions and different regulatory policies on $\mathrm{CO}_{2}$ emissions and evaluate the benefits of investing in $\mathrm{CO}_{2}$-efficient technologies. Absi et al. (2013) introduce new environmental constraints, which limit the $\mathrm{CO}_{2}$ emissions of each unit of product into a single-item uncapacitated lot-sizing problem. On the other hand, Dai (2012) implements $\mathrm{CO}_{2}$ emission constraints and a carbon tax into a lot-sizing model and solves the corresponding model using Lagrangian relaxation techniques. Similar to Dai (2012), in this thesis study, a strict $\mathrm{CO}_{2}$ emissions cap is imposed in the lot-sizing model and its impact on operational decision making is evaluated. Helmrich et al. (2011) restrict costs related to $\mathrm{CO}_{2}$ emissions released during production, inventory, and setup by defining an emission constraint, and show that the lot-sizing problem with an emission constraint is NP-hard.

Previous work has concentrated on biofuel production supply chains without analyzing the ethanol production lot sizes from various biomass sources along with corresponding economic costs and environmental impacts. Furthermore, a general multi-source capacitated lot-sizing model with $\mathrm{CO}_{2}$ emissions and water-usage constraints and associated penalties has not been encountered in the literature. The study here closes this gap by providing an MILP production planning model that minimizes both variable and fixed production costs as well as biomass purchasing and inventory holding costs of ethanol production while taking into account its environmental impacts, such as carbon and water footprints.

This study provides the following contributions to the literature. To the best of our knowledge, this is the first paper presenting an MILP capacitated lot-sizing model with $\mathrm{CO}_{2}$ emissions and water usage constraints that is applied to biofuel production. The proposed model determines the best ethanol production scenario among various biomass types in order to minimize total ethanol production, inventory holding, and biomass purchase costs. This model also penalizes excessive water usage and $\mathrm{CO}_{2}$ emissions in the objective function. In addition, it evaluates earnings from electricity produced from waste heat of biofuel production, while taking into consideration government incentive rewards, such as tax credits provided to ethanol manufacturers, in order to better understand their impact on biofuel production decisions. Furthermore, the model contributes to the literature by determining the best economically and environmentally feasible biomass sources for biofuel production under various 
conditions. A compact case study data regarding ethanol production cost, environmental impacts, and parameters from various biomass sources is also presented. This data set could be utilized by other researchers as well as managers. Finally, results of the conducted case study show that the proposed MILP model provides valuable insights and strategies for future investors, decision-makers, and the government on the cost of biofuel production using various biomass types.

The remainder of paper is organized as follows. The problem statement is provided in Chapter 2, while the mathematical model is described in detail in Chapter 3. Case study data and input parameters and their values are presented in Chapter 4 . All computational results and analyses are given in Chapter 5. Finally, concluding remarks with future directions are provided in Chapter 6. 


\section{CHAPTER 2}

\section{PROBLEM STATEMENT}

Biofuel production in an ethanol plant requires a number of consecutive decisions such as biomass source selection, amount of biomass to be purchased, amount of ethanol to be produced from the available biomass, and amount of ethanol stored while satisfying the demand for ethanol. Various factors impact an optimal ethanol production plan. For example, the type of biomass selected for ethanol production impacts the production cost and ethanol yield. Although a certain biomass type might have a high biofuel yield or low purchase cost, the penalty cost associated with $\mathrm{CO}_{2}$ emissions and water usage can be high. Since biofuel production contains some conflicting trade-offs, as stated above, it is a complex decision-making process by nature and requires adequate assessments and analyses to gain further understanding of the economic and environmental impacts of biofuel production and to ensure its sustainability. Therefore, an optimization model should be developed for biofuel production planning in order to meet economic targets while not harming the environment.

The aim of this study is to introduce an optimization framework for biofuel production by taking into account different sustainability issues such as $\mathrm{CO}_{2}$ emissions and water usage. The model introduced in this paper adopts a capacitated lot-sizing approach in which the amount of production capacity and available biomass feedstock are limited. The model considers first- and second-generation biomass feedstocks that would be used for ethanol production. The total biofuel production cost is minimized in this model while determining the optimal design of a biofuel production system based on the following:

- Amount of biomass purchased from each biomass type in each period.

- Amount of biofuel produced from each biomass type in each period.

- Amount of biofuel inventory held in each period.

- $\mathrm{CO}_{2}$ emissions released and total water used during biofuel production in each period.

- Penalty and incentive amounts for $\mathrm{CO}_{2}$ emissions of biofuel production. 


\section{CHAPTER 3}

\section{MATHEMATICAL MODEL}

An MILP model is formulated for minimizing the total cost of ethanol production as well as its negative environmental impacts. The optimal levels for various decisions regarding production volumes, biomass preferences, budget allocation to various cost elements, and inventory held are determined by solving the MILP model. A detailed explanation of the objective function and constraints of the proposed model are given in the following sections.

\subsection{Objective Function}

The objective function of the MILP model includes production costs, setup costs, and biomass purchasing costs minus a tax credit for each gallon of ethanol produced and income from electricity production, as well as inventory holding costs, a $\mathrm{CO}_{2}$ tax penalty for the excessive amount of $\mathrm{CO}_{2}$ emissions released, and a penalty for excessive water usage during production, given as

$$
\left.\min \sum_{t=1}^{T} \sum_{i=1}^{I}\left(p_{i t} X_{i t}+f_{i t} Y_{i t}+r_{i} M_{i t}-\left(v X_{i t}+k X_{i t}\right)\right)+\left(h_{t} I_{t}+z U_{t}+\mu S_{t}\right)\right)
$$

\subsection{Production and Capacity Constraints}

Constraint (2) ensures that the amount of ethanol produced from biomass type $i$ in period $t$ is equal to the amount of biomass used from biomass type $i, M_{i t}$, multiplied by the conversion factor in period $t$, and is defined as

$$
X_{i t}=e_{i} M_{i t} \quad \forall i, t
$$

Constraint (3) implies that the amount of biomass used from biomass type $i$ in period $t$ cannot exceed the available biomass amount for purchase from biomass type $i$ in period $t$ :

$$
M_{i t} \leq b_{i t} \quad \forall i, t
$$

Constraint (4) is the inventory balance constraint, which ensures that the sum of total ethanol production in period $t$ and ending inventory in period $t-1$ is equal to the sum of demand and inventory in period $t$ :

$$
\sum_{i=1}^{I} X_{i t}+I_{t-1}=d_{t}+I_{t} \quad \forall t
$$


Constraint (5) limits the total production amount to the minimum of the capacity of the facility at time period $t$ or the total demand in future periods as

$$
\sum_{i=1}^{I} X_{i t} \leq \min \left\{q_{t}, \sum_{j=t}^{T} d_{j}\right\} \quad \forall t
$$

Constraint (6) ensures that the binary setup variable, $Y_{i t}$, is 1 whenever $X_{i t}$ is positive:

$$
X_{i t} \leq q_{t} Y_{i t} \quad \forall i, t
$$

\subsection{Environmental Constraints}

Constraint (7) defines the cap for $\mathrm{CO}_{2}$ emissions that occur during the ethanol production step as

$$
\sum_{i=1}^{I} \hat{p}_{i t} X_{i t} \leq c_{t}+U_{t} \quad \forall t
$$

Note that $U_{t}$ defines $\mathrm{CO}_{2}$ emissions exceeding the predefined emission cap in period $t$ and is penalized in the objective function (1).

Constraint (8) ensures that water consumed during the production of ethanol cannot exceed water cap $\Omega_{t}$. Similar to the $\mathrm{CO}_{2}$ emissions case, the exceeding amount, $\mathrm{S}_{\mathrm{t}}$, is penalized in the objective function (1). The water emission constraint is given as

$$
\sum_{i=1}^{I} w_{i t} X_{i t} \leq \Omega_{t}+S_{t} \quad \forall t
$$

\subsection{Bounds on Variables}

Constraints (9), (10), and (11) are bounds and integer restrictions on the variables:

$$
\begin{aligned}
& X_{i t} \geq 0, M_{i t} \geq 0 \quad \forall i, t \\
& I_{t} \geq 0, U_{t} \geq 0, S_{t} \geq 0 \quad \forall t \\
& Y_{i t} \in\{0,1\} \quad \forall i, t
\end{aligned}
$$




\section{CHAPTER 4}

\section{CASE STUDY DATA AND INPUT PARAMETERS}

This section presents data gathered from several resources for defining the case study and solving the model. Since different biomass types are available, for some parameters, various available sources are taken into consideration, in order to compile and calculate the model data.

\subsection{Production Cost}

Production cost includes both variable and fixed production costs, which are presented in the following two subsections.

\subsubsection{Variable Production Cost}

Data regarding the variable cost of producing ethanol from various biomass sources are presented in Table 1 (Bain, 2007). The variable production cost includes the cost of several components - catalysts, chemicals, electricity, natural gas, water, and utilities - depending on the amount of ethanol produced and the type of biomass used. The main factor leading to different ethanol production costs from different biomass types is the amount of energy and chemicals required to initiate fermentation.

TABLE 1

VARIABLE AND FIXED PRODUCTION COST DATA

\begin{tabular}{|c|c|c|}
\hline Biomass Source & $\begin{array}{c}\text { Variable } \\
\text { Production Cost } \\
\text { (\$/Gallon ethanol) }\end{array}$ & $\begin{array}{c}\text { Fixed } \\
\text { Production Cost } \\
\text { (\$) }\end{array}$ \\
\hline Switchgrass & 0.23 & 480,769 \\
\hline Sugarcane & 0.27 & 96,154 \\
\hline Corn & 0.33 & 134,615 \\
\hline Wheat & 0.33 & 134,615 \\
\hline
\end{tabular}

\subsubsection{Fixed Production Cost}

The fixed cost in ethanol production includes labor, maintenance, general overhead, direct overhead, and insurance. The fixed cost is charged when the ethanol production is initiated using a 
different biomass type in a given production period. Table 1 shows data regarding the fixed cost of producing ethanol from each biomass type at a plant with production capacity of $50 \mathrm{M}$ gallons a year (Bain, 2007). The fixed cost per gallon of ethanol for each biomass type is multiplied by the total amount of production capacity for a single period, which is $2.08 \mathrm{M}$ gallons, in order to find a one-time fixed cost in a period of two weeks.

\subsection{Inventory Holding Cost}

The inventory holding cost represents the cost of ethanol inventory held in each period. The approximate inventory holding cost is $\$ 0.084$ per gallon of ethanol (McAloon et al., 2000).

\subsection{Feedstock Purchasing Cost}

The purchasing cost of each biomass type is given in Table 2. The purchasing costs of corn and wheat are relatively high because of their use in food production.

\subsection{Feedstock Conversion Factors}

The conversion factor is one of the most critical parameters since it defines the rate of ethanol conversion from the biomass source. Table 2 presents the feedstock purchasing costs and gallons of ethanol produced from a ton of each biomass type.

TABLE 2

FEEDSTOCK PURCHASING COST AND BIOFUEL CONVERSION FACTORS

\begin{tabular}{|c|c|c|c|c|}
\hline \multirow{2}{*}{$\begin{array}{l}\text { Biomass } \\
\text { Resource }\end{array}$} & \multicolumn{2}{|c|}{ Feedstock Purchasing Cost } & \multicolumn{2}{|c|}{ Biofuel Conversion Factors } \\
\hline & $\begin{array}{l}\text { Value } \\
\text { (\$/ton) }\end{array}$ & Resource & $\begin{array}{c}\text { Value } \\
\text { (gallons/ton) }\end{array}$ & Resource \\
\hline Switchgrass & 65 & $\begin{array}{l}\text { University of Kentucky, } \\
2013\end{array}$ & 90 & Schmer, 2008 \\
\hline Sugarcane & 29 & Bain, 2007 & 19.5 & $\begin{array}{l}\text { United States Department } \\
\text { of Agriculture, } 2006\end{array}$ \\
\hline Corn & 107 & Bain, 2007 & 98.21 & $\begin{array}{l}\text { United States Department } \\
\text { of Agriculture, } 2006\end{array}$ \\
\hline Wheat & 113 & Bain, 2007 & 103.7 & $\begin{array}{l}\text { United States Department } \\
\text { of Agriculture, } 2006\end{array}$ \\
\hline
\end{tabular}




\subsection{Electricity Production}

Electricity is produced in biofuel plants by using a waste-heat boiler that generates steam from an oxidizer. Furthermore, any excess electricity is sold to the local power grid (United States Environmental Protection Agency, 2007). Electricity production for each gallon is credited by $\$ 0.111$ (McAloon et al., 2000).

\subsection{Water Usage}

The model also tracks the amount of water consumed during ethanol production and penalizes its excessive usage. Table 3 shows the amount of water required to produce a gallon of ethanol for each considered biomass source.

\section{TABLE 3}

WATER USAGE AND $\mathrm{CO}_{2}$ EMISSIONS RELEASED

\begin{tabular}{|c|c|c|c|c|}
\hline \multirow[b]{2}{*}{$\begin{array}{l}\text { Biomass } \\
\text { Resource }\end{array}$} & \multicolumn{2}{|c|}{ Water Usage } & \multicolumn{2}{|c|}{$\mathrm{CO}_{2}$ Emissions } \\
\hline & $\begin{array}{c}\text { Value } \\
\text { (gallon/gallon } \\
\text { ethanol) }\end{array}$ & Resource & $\begin{array}{c}\text { Value } \\
\text { (kg/gallon } \\
\text { ethanol) }\end{array}$ & Resource \\
\hline Switchgrass & 5.4 & Aden, 2007 & 0.434 & $\begin{array}{l}\text { Levelton Engineering Ltd., } \\
2000\end{array}$ \\
\hline Sugarcane & 5.4 & $\begin{array}{l}\text { Goldemberg et al., } \\
2008\end{array}$ & 0.1520 & $\begin{array}{c}\text { California Environmental } \\
\text { Protection Agency Air } \\
\text { Resources Board, } 2009\end{array}$ \\
\hline Corn & 3 & Aden, 2007 & 2.370 & $\begin{array}{l}\text { Levelton Engineering Ltd., } \\
2000\end{array}$ \\
\hline Wheat & 1.58 & Saunders et al., 2011 & 0.5070 & $\begin{array}{l}\text { Levelton Engineering Ltd., } \\
2000\end{array}$ \\
\hline
\end{tabular}

\section{7 $\quad \mathrm{CO}_{2}$ Emissions}

$\mathrm{CO}_{2}$ emissions include process emissions, combustion emissions, fugitive emissions, and chemical life-cycle emissions. $\mathrm{CO}_{2}$ emissions $(\mathrm{kg})$ per million British thermal units (BTUs) for all biomass sources are obtained from sources listed in Table 3. For switchgrass, this is $5.73 \mathrm{~kg}$, for sugarcane $2.02 \mathrm{~kg}$, for corn $31.32 \mathrm{~kg}$, and for wheat $6.70 \mathrm{~kg}$ of $\mathrm{CO}_{2}$ per million BTUs. It is stated that 13.21 gallons ethanol produces one million BTUs (United States Department of Energy, 2012). 
Therefore, $\mathrm{CO}_{2}$ emissions $(\mathrm{kg})$ per gallon of ethanol from each biomass source shown in Table 3 are found by dividing the $\mathrm{CO}_{2}$ per million BTU value by 13.21 .

\section{8 $\mathrm{CO}_{2}$ Tax Penalty and Tax Credit}

$\mathrm{A} \mathrm{CO}_{2}$ tax penalty is a tax imposed on $\mathrm{CO}_{2}$ and other possible greenhouse gas emissions during ethanol production. Currently, there is no $\mathrm{CO}_{2}$ tax penalty for excessive $\mathrm{CO}_{2}$ emissions in the United States. The $\mathrm{CO}_{2}$ tax penalty in the model is chosen as $\$ 20$ per ton of $\mathrm{CO}_{2}$ released, which is similar to a case study by the National Association of Manufacturers (2009). The U.S. government is offering a tax credit of $\$ 0.45$ per gallon of ethanol produced (Maley, 2012). This tax credit is implemented in the model by rewarding each gallon of ethanol produced from any biomass source.

\subsection{Water Usage Penalty}

Currently there are no regulations for excessive water usage in industry in the U.S. (Aden, 2007). However, it is assumed that each gallon of excessive water usage is penalized with its purchasing cost, which equals \$0.00314 in Kansas (City of Lawrence, Kansas, 2013).

\subsection{Demand and Capacity}

This section provides a detailed discussion of how the values for demand, biomass availability, $\mathrm{CO}_{2}$ emissions cap, and water usage cap are determined.

\subsubsection{Demand}

The demand for each period is calculated by randomly generating data based on a uniform distribution. The range of random generation is taken between 60 and 80 percent of the period-based capacity, which is $2.6 \mathrm{M}$ gallons.

\subsubsection{Biomass Availability}

The amount of capacity available in a period is divided by four in order to find the amount of ethanol in gallons to be produced from each biomass. Then these values are divided by the corresponding biomass conversion factors in order to compute the amount of biomass needed from each source in tons. In addition, biomass availability for switchgrass, sugarcane, corn, and wheat is set to $5.87 \mathrm{~K}$ tons, $27.12 \mathrm{~K}$ tons, $5.38 \mathrm{~K}$ tons, and $5.09 \mathrm{~K}$ tons, respectively. 


\subsection{3 $\mathrm{CO}_{2}$ Emissions Cap}

The $\mathrm{CO}_{2}$ emissions cap for each period is calculated by multiplying the average $\mathrm{CO}_{2}$ emissions released from all biomass types with the average demand in each period. In the base case, the $\mathrm{CO}_{2}$ emissions cap is set at 60 percent of the average possible emissions, which is equal to $351.17 \mathrm{~K}$ tons that can occur in a period. In this study, the value of the $\mathrm{CO}_{2}$ cap is set so that it does not affect production undesirably.

\subsubsection{Water Usage Cap}

Similar to the $\mathrm{CO}_{2}$ emissions cap, the average amount of water usage per gallon of ethanol is multiplied by ethanol demand in a period to find the average amount of total water usage. This results in a value of $8.9 \mathrm{M}$ gallons and is used as the water usage cap in each period. 


\section{CHAPTER 5}

\section{COMPUTATIONAL RESULTS}

The MILP model presented in Chapter 3 is applied to a case study in Kansas considering a comprehensive biofuel production system using switchgrass, sugarcane, corn, and wheat. In Kansas, currently 11 ethanol plants are producing 440 million gallons of ethanol a year (Ross, 2011). In this case study, Abengoa Bioenergy's Hugoton plant is considered the reference for applying the model developed here. The Hugoton plant has a yearly production capacity of 55 million gallons. The plant uses corn, wheat, and switchgrass as its main biomass supply (Abengoa Bioenergy, 2011). This study considers a one-year planning horizon consisting of 26 periods, where each period represents a timeframe of two weeks. The length of each period is determined based on the plant production schedule of Abengoa Bioenergy LLC in Hugoton, Kansas.

The proposed MILP model is solved by using the IBM Ilog Cplex $12.5^{\circ}$ (IBM ILOG, 2012) on a computer with a $1.70 \mathrm{GHz}$ Intel i5 CPU and $8.0 \mathrm{~GB}$ of memory. Table 4 presents four different sets of experiments corresponding to the demand, emissions cap, water cap, and available biomass parameters, respectively. The first four columns correspond to these four different parameters that are investigated, while the last five columns present the objective function value, profit, profitability, water penalty cost, and $\mathrm{CO}_{2}$ emissions cost for each case, respectively. In each set of experiments, three parameters are fixed to the base case values, while the other parameter is set to three different values (base, low, and high) for analyzing the impact of the corresponding parameters. Furthermore, for observing the efficiency of each biomass type without a supply limit, an unlimited biomass availability case and four different cases where only one type of biomass-based production is allowed with unlimited biomass availability are considered. All instances considered in Table 4 are solved in less than 5 CPU seconds.

The objective function value representing total minimum costs is $\$ 46.55 \mathrm{M}$ in the base case where the total amount of demand (38.8 M gallons) is satisfied 100 percent. Wheat fulfills the highest percentage due to the corresponding low variable and fixed ethanol production costs compared to other 
considered biomass sources. Similarly, corn and switchgrass meet the second and third highest percentages of total demand because of their conversion-rate advantage compared to sugarcane. Even though sugarcane has a lower feedstock purchasing cost, its low conversion factor makes it less preferable compared to other biomass types.

\section{TABLE 4}

COMPUTATIONAL RESULTS FOR DIFFERENT EXPERIMENTAL DESIGNS

\begin{tabular}{|c|c|c|c|c|c|c|c|c|}
\hline Demand & $\begin{array}{c}\text { Emissions } \\
\text { Cap }\end{array}$ & $\begin{array}{c}\text { Water } \\
\text { Cap }\end{array}$ & $\begin{array}{c}\text { Available } \\
\text { Biomass }\end{array}$ & $\begin{array}{c}\text { Objective } \\
\text { Function } \\
\text { Value/Total } \\
\mathbf{C o s t} \\
\mathbf{( \$ M )}\end{array}$ & $\begin{array}{c}\text { Revenue } \\
\mathbf{( \$ M )}\end{array}$ & Profitability & $\begin{array}{c}\text { Water } \\
\text { Penalty } \\
\text { Cost } \\
\mathbf{( \$ K )}\end{array}$ & $\begin{array}{c}\mathbf{C O}_{\mathbf{2}} \\
\text { Emissions } \\
\text { Penalty } \\
\text { Cost } \\
\mathbf{( \$ K )}\end{array}$ \\
\hline Base & Base & Base & Base & 46.55 & 70.45 & 1.51 & 24.08 & 704.40 \\
\hline Low & Base & Base & Base & 26.07 & 41.14 & 1.57 & 0.00 & 398.40 \\
\hline High & Base & Base & Base & 65.05 & 94.88 & 1.45 & 219.43 & 766.61 \\
\hline Base & Low & Base & Base & 46.66 & 70.45 & 1.50 & 24.08 & 813.11 \\
\hline Base & High & Base & Base & 45.85 & 70.45 & 1.53 & 24.08 & 0.00 \\
\hline Base & Base & Low & Base & 46.83 & 70.45 & 1.50 & 299.02 & 704.40 \\
\hline Base & Base & High & Base & 46.53 & 70.45 & 1.51 & 0.00 & 704.40 \\
\hline Base & Base & Base & Unlimited & 26.49 & 70.45 & 2.65 & 367.07 & 212.49 \\
\hline Base & Base & Base & Low & 53.11 & 70.45 & 1.32 & 75.75 & 519.90 \\
\hline Base & Base & Base & High & 40.36 & 70.45 & 1.74 & 33.32 & 195.73 \\
\hline Base & Base & Base & $\begin{array}{c}\text { Switchgrass } \\
\text { only }\end{array}$ & 26.49 & 70.45 & 2.65 & 367.07 & 212.49 \\
\hline Base & Base & Base & $\begin{array}{c}\text { Sugarcane } \\
\text { only }\end{array}$ & 49.19 & 70.45 & 1.43 & 259.81 & 0.00 \\
\hline Base & Base & Base & Corn only & 38.47 & 70.45 & 1.83 & 0.91 & $1,648.79$ \\
\hline Base & Base & Base & Wheat only & 37.05 & 70.45 & 1.90 & 0.00 & 224.38 \\
\hline
\end{tabular}

Ethanol sales income is calculated by multiplying total production amount with the current sale price of ethanol, which is $\$ 1.815$ per gallon (Kment, 2014). Furthermore, profitability is calculated by dividing the total revenue to the objective function value (minimum total cost) of the respective case.

Figure 1 shows the profitability values for the base, low, and high demand cases, as well as several biomass availability cases. Profitability is 1.51 in the base case, which is considered a reference point for this case study. Surprisingly, in the low-demand case, profitability increases up to 1.57 , while in 
the high-demand case, profitability decreases to 1.45 . This can be explained by the increase in fixed costs for additional production to satisfy increased demand under limited availability of the most profitable biomass types. In addition, high production volume causes extensive amounts of $\mathrm{CO}_{2}$ emissions and water usage, thus resulting in additional tax penalties. In the unlimited biomass availability case, which is equivalent to the switchgrass-only case, profitability increases to 2.65 because of the usage of only switchgrass with a single fixed production cost. Sugarcane-only, corn-only, and wheat-only cases have relatively low profitability due to their higher production costs compared to switchgrass. Although not shown in Figure 1 but as presented in Table 4, it can be seen that reducing the $\mathrm{CO}_{2}$ emissions and water usage caps has a slightly adverse impact on the base case results in terms of costs and profitability because the associated penalty costs are much smaller than production-related costs.

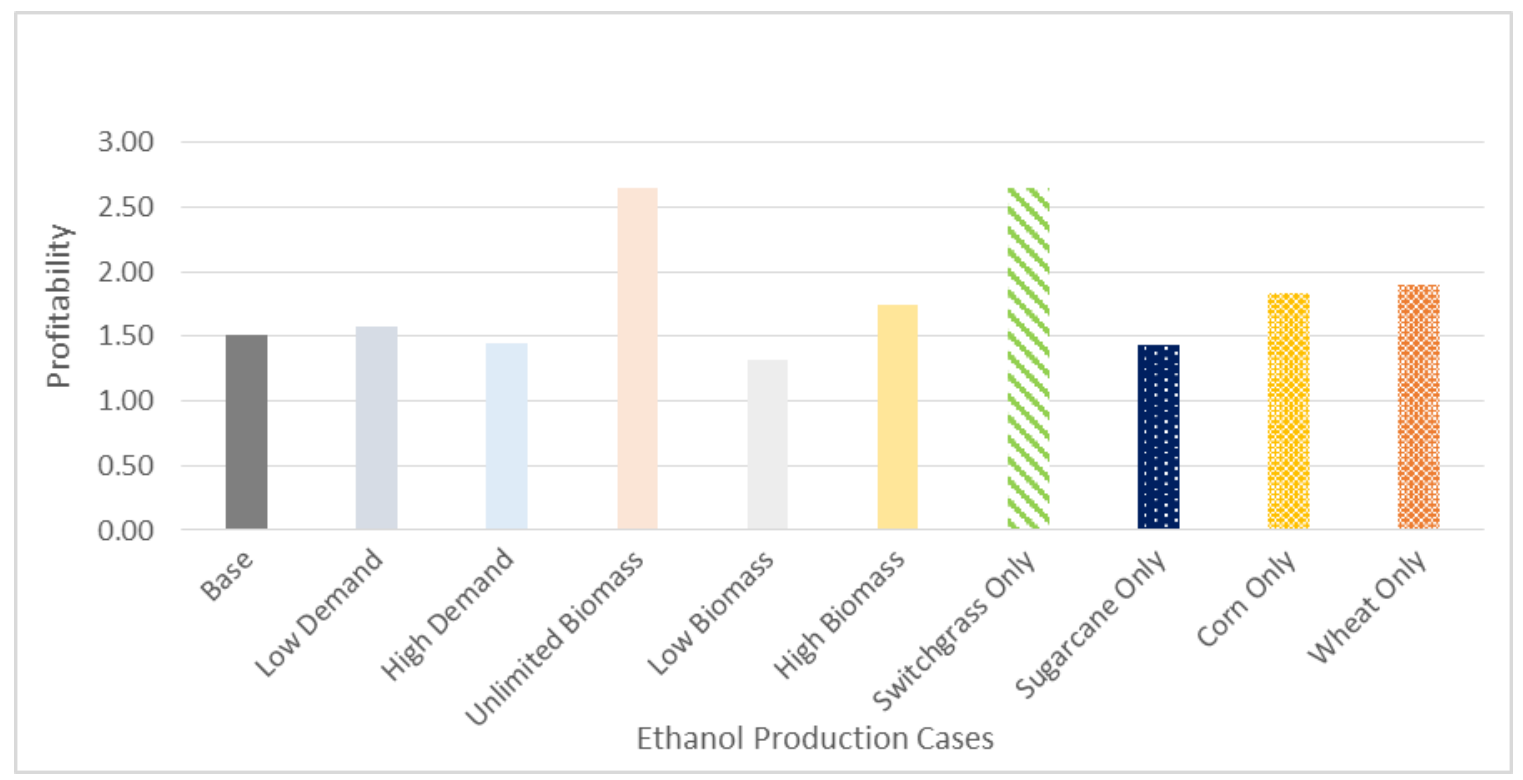

Figure 1. Profitability of biomass production

Figure 2 displays the cost breakdown for various cost elements in ethanol production. As shown, the biomass purchasing cost is higher than any other costs because of the high biomass purchasing costs. Furthermore, fixed production costs are the second highest cost since more than one biomass types is used in each period, resulting in multiple fixed production costs. A total tax income of $\$ 17.46 \mathrm{~K}$ is obtained 
from government ethanol incentives, while converting excessive heat into electricity for production leads to a savings of $\$ 4.30 \mathrm{M}$ through all production periods.

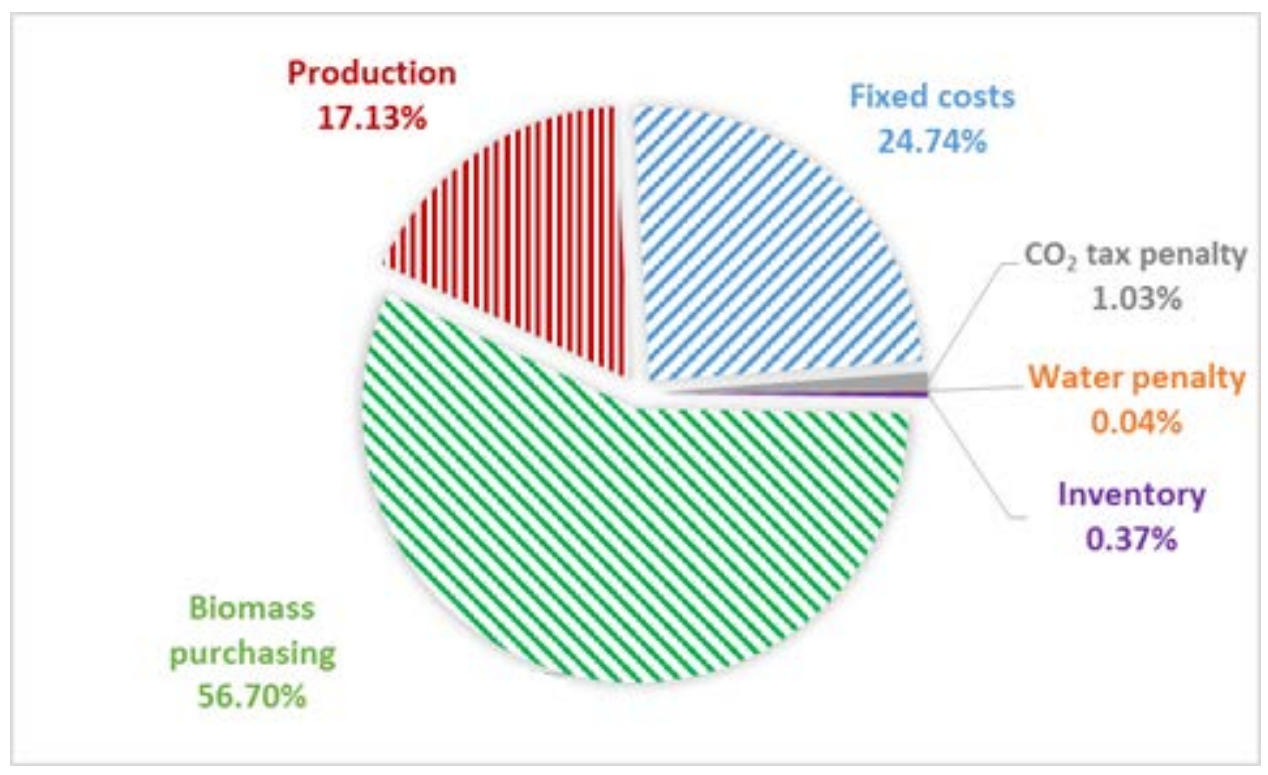

Figure 2. Cost breakdown of annual ethanol production

Figure 3(a) displays the percentage breakdown of total used biomass, and Figure 3(b) presents the total produced ethanol. Although sugarcane meets 2.16 percent of total ethanol production, it comprises 9.94 percent of the total amount of biomass used due to its low conversion factor, as discussed previously.
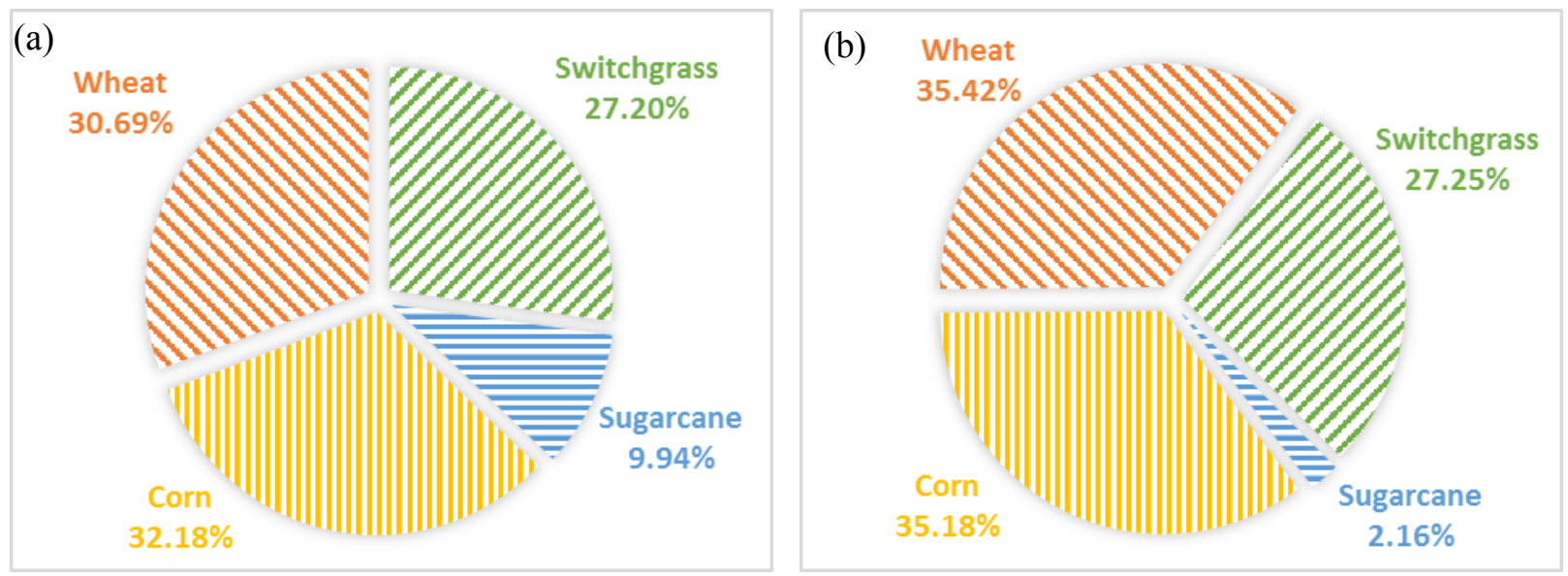

Figure 3. Breakdown of total used biomass (a) and breakdown of total produced ethanol (b)

Figure 4 shows the environmental impacts of biomass types with respect to their $\mathrm{CO}_{2}$ emissions and water usage. The total amount of $\mathrm{CO}_{2}$ emissions released during the entire production timeline is 
3.85M tons, as shown in Figure 4(a). In addition to emission releases, each biomass type has different water-usage requirements for ethanol conversion (Aden, 2007). As shown in Figure 4(b), even though 27.25 percent of the total biofuel produced comes from switchgrass, its high water usage causes 45.94 percent of total water usage. On the other hand, corn requires 32.95 percent of total water usage, while it meets 35.18 percent of total ethanol production.
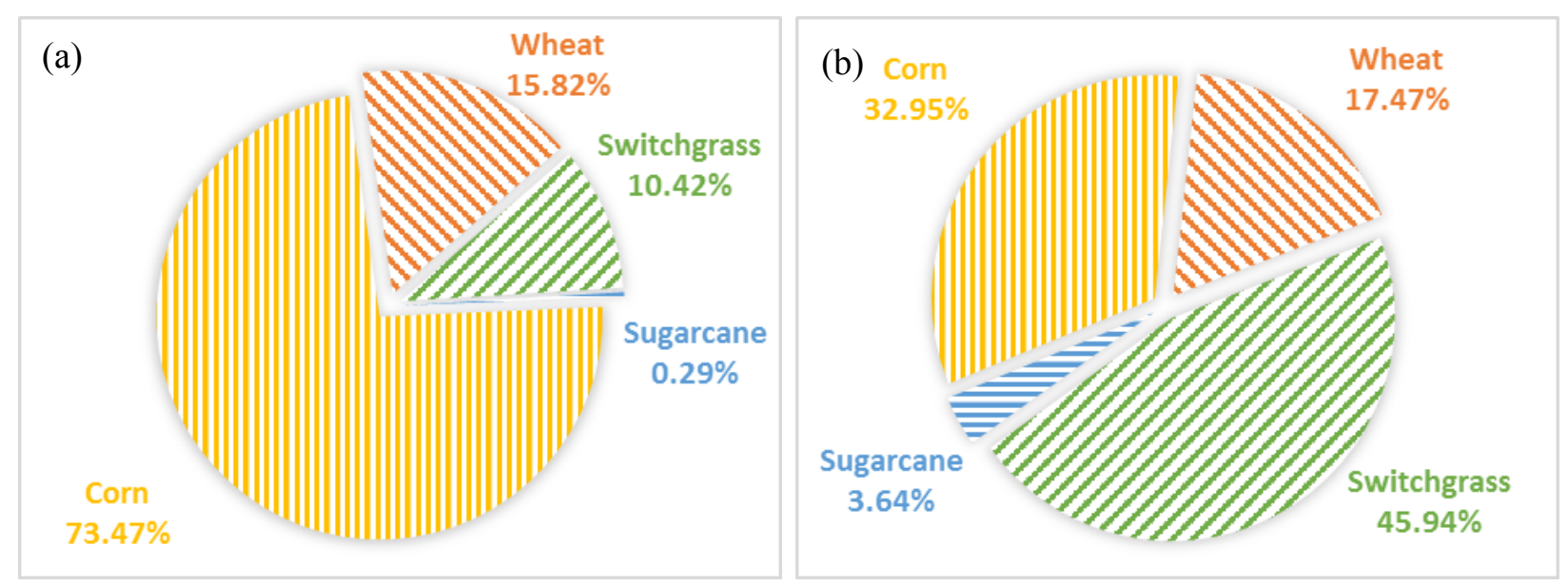

Figure 4. Breakdown of total $\mathrm{CO}_{2}$ emissions (a) and breakdown of total water usage (b)

Figure 5 shows a 26-period (one-year) ethanol production timeline for four biomass types and the inventory held for the base case. It can be seen that corn, wheat, and switchgrass are the most preferred biomass sources for ethanol production. Additional amounts of ethanol produced are kept as inventory in order to save from the fixed cost in future periods. The primary use of corn, wheat, and switchgrass for ethanol production is preferred over sugarcane because of their high conversion factors compared to that of sugarcane. 


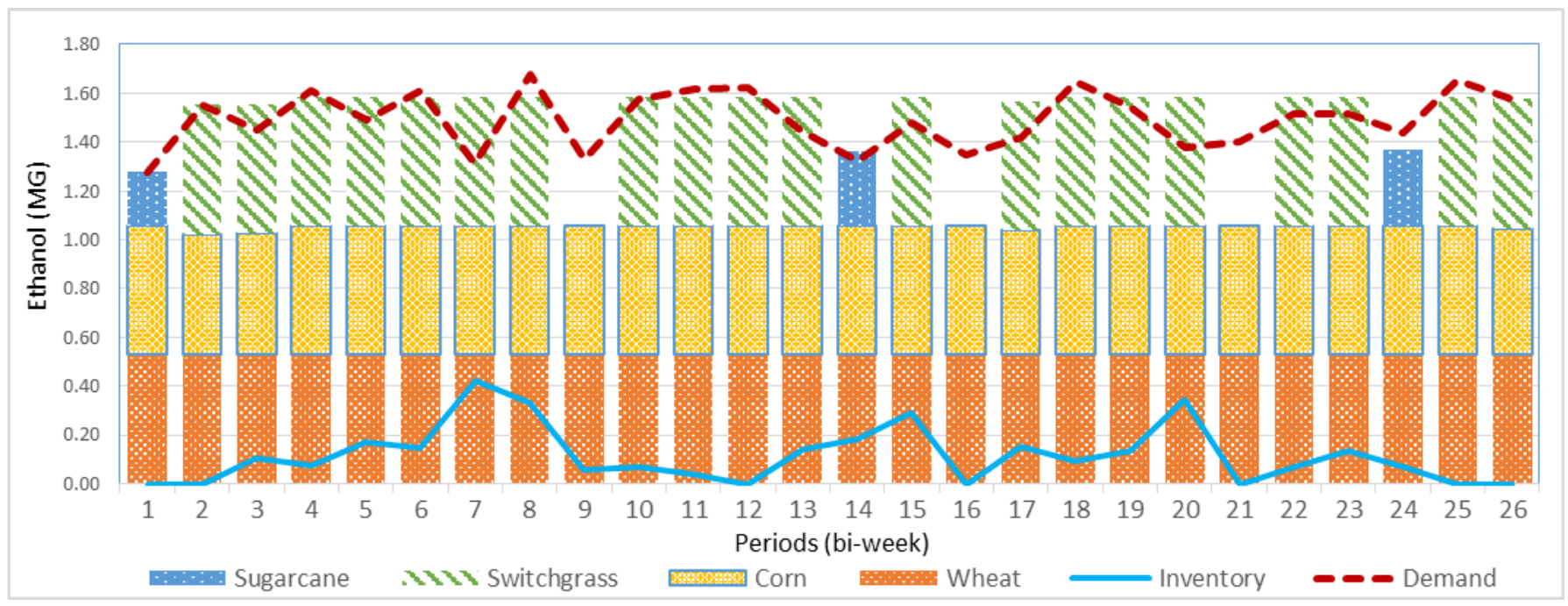

Figure 5. Ethanol production timeline including produced ethanol and inventory held in base case

In the following sections, various scenarios are evaluated by altering several different parameters for analyzing results of the MILP model. The first analysis focuses on the impact of different demand levels, and the second analysis investigates the effect of the $\mathrm{CO}_{2}$ tax penalty on production and the optimal solution. The third and fourth experiments determine the impact of $\mathrm{CO}_{2}$ emissions and the waterusage cap. The last experiment is based on possible technology improvements and their impact on ethanol production.

\subsection{Impact of Demand on Results}

Two different demand cases are examined for understanding their impact on the results. In the base case, demand is uniformly distributed between 60 and 80 percent of total capacity. For the lowdemand case, demand is uniformly distributed between 30 and 50 percent of total capacity. For the highdemand case, demand is uniformly distributed between 90 and 100 percent of capacity. As shown in Figure 6(a), decreasing the amount of demand eliminates the use of switchgrass and sugarcane. Here, ethanol is mainly produced from wheat, and for the periods where wheat cannot meet the demand by itself, corn is also used. For those periods where corn is used for supporting ethanol production, ethanol is produced at the highest possible amount and placed in inventory to be used in future cases when wheatbased ethanol cannot meet the demand. One possible reason for this preference is that the inventory 
holding cost for several periods is less costly than an additional setup cost. Figure 6(b) shows the total production cost breakdown in the low-demand case. Here, fixed production costs decrease to 15.27 percent because the variety of biomass sources is reduced compared to the base case.

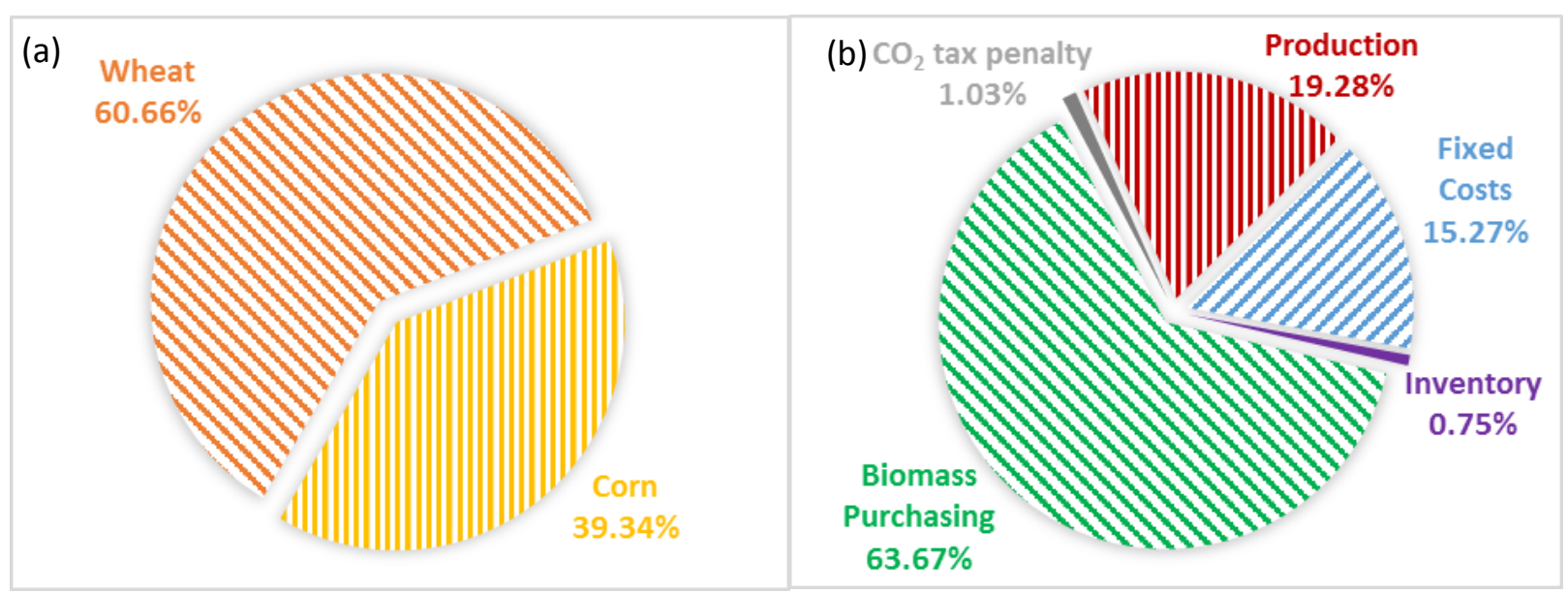

Figure 6. Breakdown of total ethanol production for low-demand case (a) and breakdown of total production cost for low-demand case (b)

In the high demand case, the MILP model uses all biomass types since high demand requires utilization of all limited biomass sources, as shown in Figure 7(a). Compared to the base case, the biomass purchasing cost increases to 59.64 percent, while the fixed cost decreases to 23.00 percent, as shown in Figure $7(\mathrm{~b})$. The emissions penalty is $\$ 766.61 \mathrm{~K}$ because of the total exceeding emissions of $4,292.36 \mathrm{~K}$ tons, which is 0.81 percent of the total cost. The total excessive water usage penalty is $\$ 239 \mathrm{~K}$ due to total exceeding water usage of $69.88 \mathrm{M}$ gallons, which consists of less than 1 percent of total costs. 


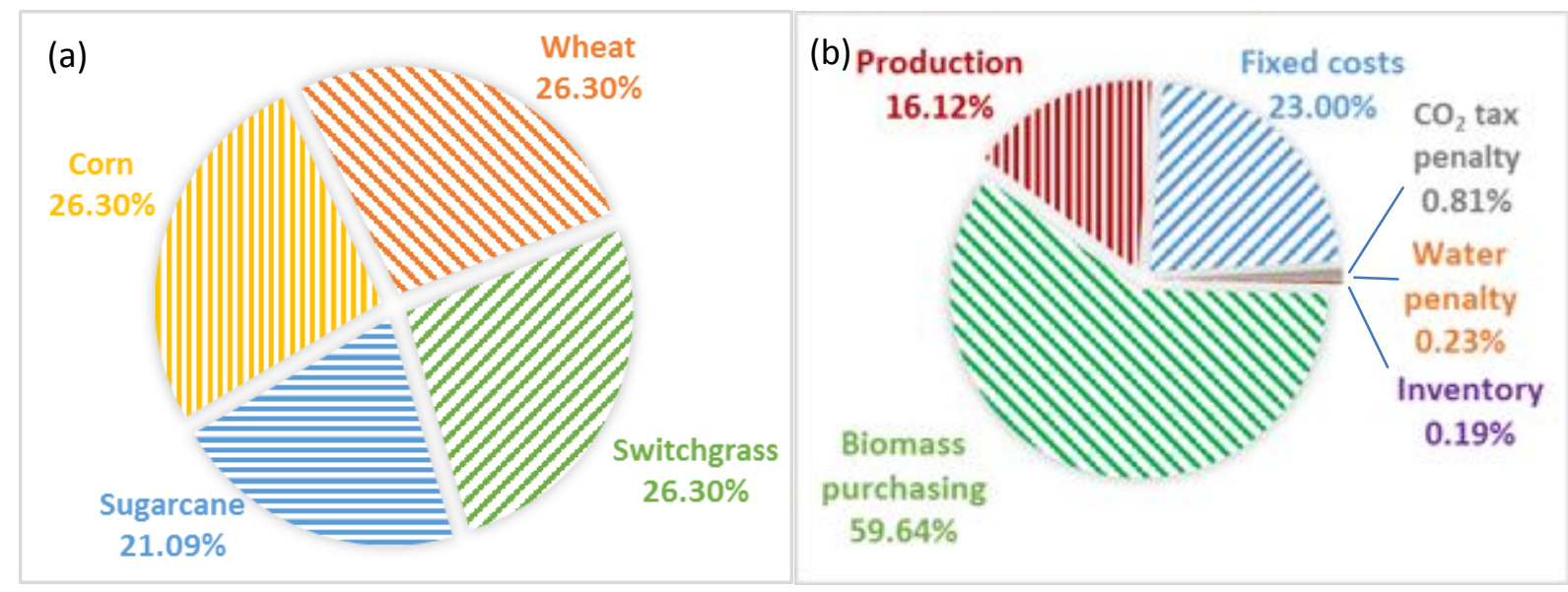

Figure 7. Breakdown of total ethanol production for high-demand case (a) and breakdown of total production cost for high-demand case (b)

\subsection{Impact of Biomass Availability on Results}

Seven different biomass availability cases-unlimited, low, high, switchgrass only, sugarcane only, corn only, and wheat only_are examined here for understanding their impact on the results. In the unlimited biomass availability case, all biomass sources are assumed to have unlimited availability for ethanol production. For the low-biomass availability case, biomass availability is reduced to 75 percent of the base case amount. Similarly, for the high-biomass availability case, biomass availability is increased to 145 percent of the base case amount. In addition to these three cases, four cases where biomass availability is allowed for only one kind of biomass in each case are studied. Similar to the previous experiment, the cost breakdown among different operations, the ethanol production amounts from each biomass type, and the amount of $\mathrm{CO}_{2}$ emissions released under different cases are determined.

Figure 8 shows the total cost breakdown in the unlimited biomass availability case. Here, the production priority of the model is given to only switchgrass in all periods because its variable production cost is lower than other biomass types. Since switchgrass can satisfy demand by itself, only one fixed production cost occurs, thus decreasing the impact of the fixed production cost on total cost. In this case, the inventory holding cost is increased to 3.30 percent because in each period, the model uses the maximum available capacity and keeps the inventory for several periods to avoid fixed production costs as much as possible by meeting the demand in a given period by using only the inventory. 


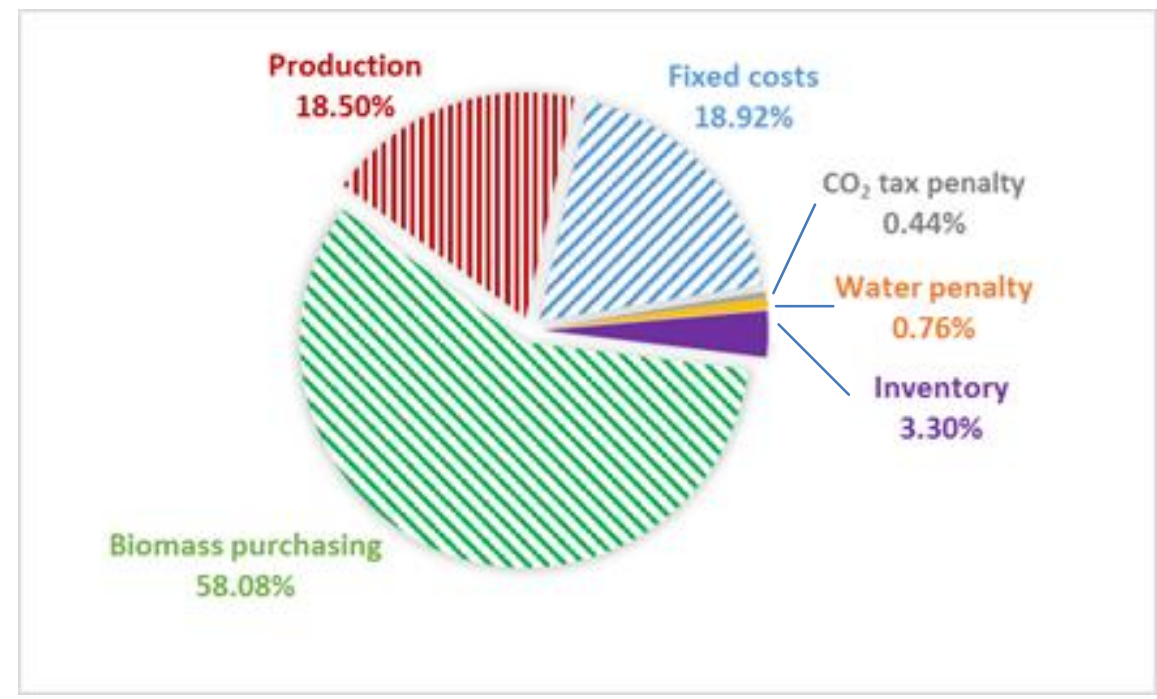

Figure 8: Breakdown of total production cost for unlimited biomass availablity case Figure 9(a) shows the impact of low-biomass availability on optimal production preferences. In this case, in addition to wheat, corn, and switchgrass, the MILP model prefers to use sugarcane for meeting the demand due to low-biomass availability. It can be seen that the fixed cost increases to 25.52 percent due to the used biomass variability compared to the base case, as shown in Figure 9(b). The emission penalty paid is $\$ 519.90 \mathrm{~K}$ because of the total exceeding emissions of $2.86 \mathrm{M}$ tons, while the total excessive water usage penalty is $75.75 \mathrm{~K}$ due to total exceeding water usage of $24.12 \mathrm{M}$ gallons.
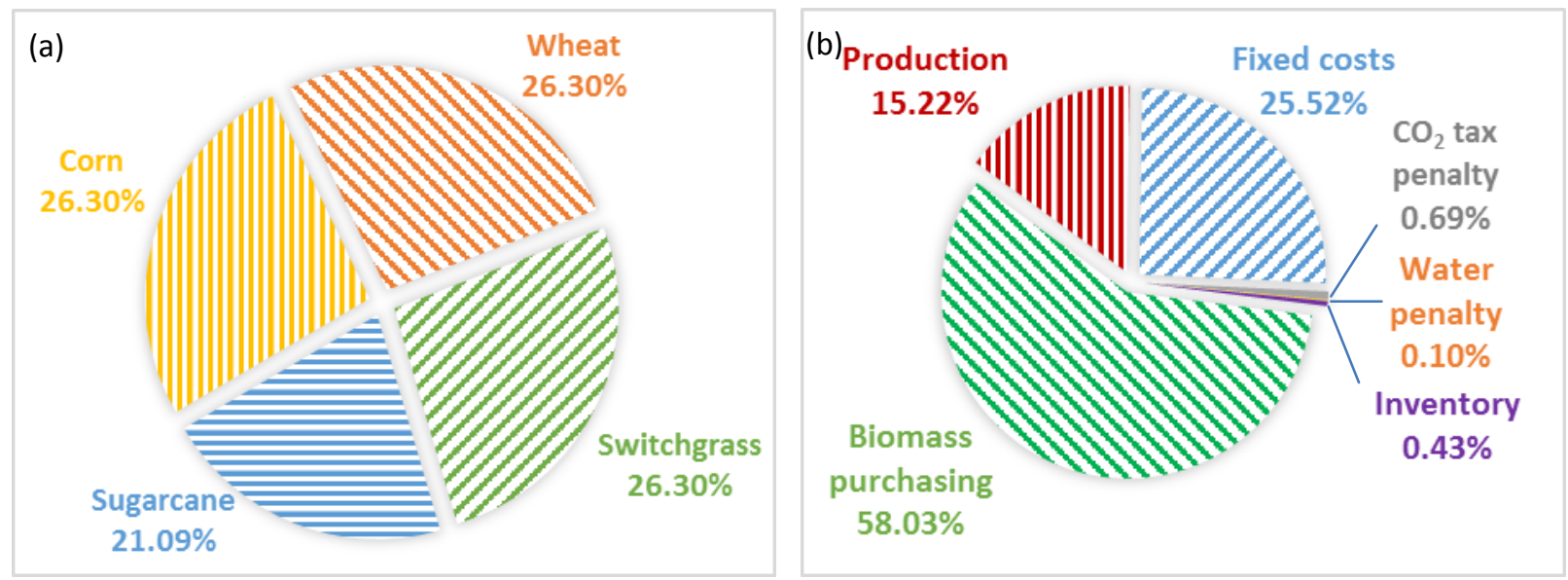

Figure 9. Breakdown of total ethanol production for low-biomass availability case (a) and breakdown of total production cost for low-biomass availability case (b)

It can be seen that high-demand and low-biomass availability cases have a similar impact on the results, in terms of the increase in total costs and decrease in profitability. The breakdown of total ethanol 
production and the breakdown of total production cost in the high-biomass availability case are shown in Figures 10(a) and 10(b). In this case, only switchgrass and wheat are used for biofuel production, as shown in Figure 10(a). Switchgrass and wheat are preferred because of their low production cost compared to other biomass types.

Figure 11 shows the cumulative $\mathrm{CO}_{2}$ emissions released during 26 periods (52 weeks) of using only one biomass source for each type of biomass. This also proves that in addition to the financial profitability of switchgrass, it is also one of the most $\mathrm{CO}_{2}$ emissions-friendly biomass sources for ethanol production after sugarcane.
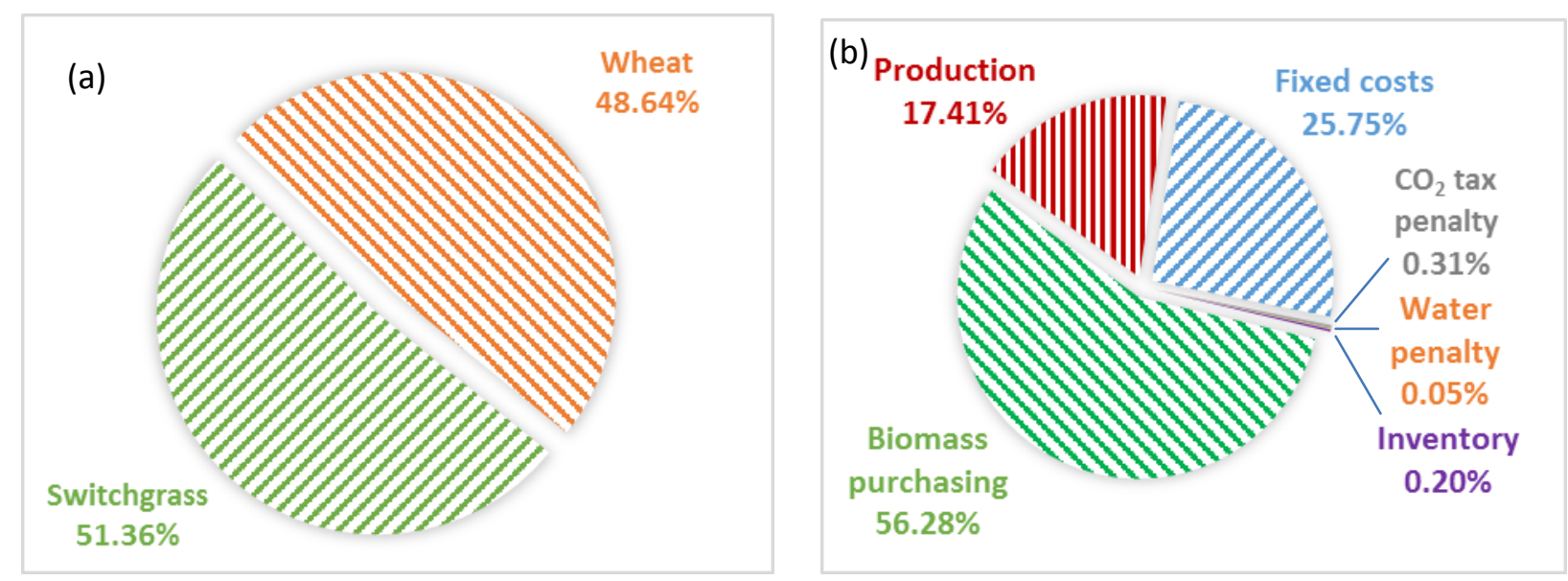

Figure 10. Breakdown of total ethanol production for high-biomass availability case (a) and breakdown of total production cost for high-biomass availability case (b)

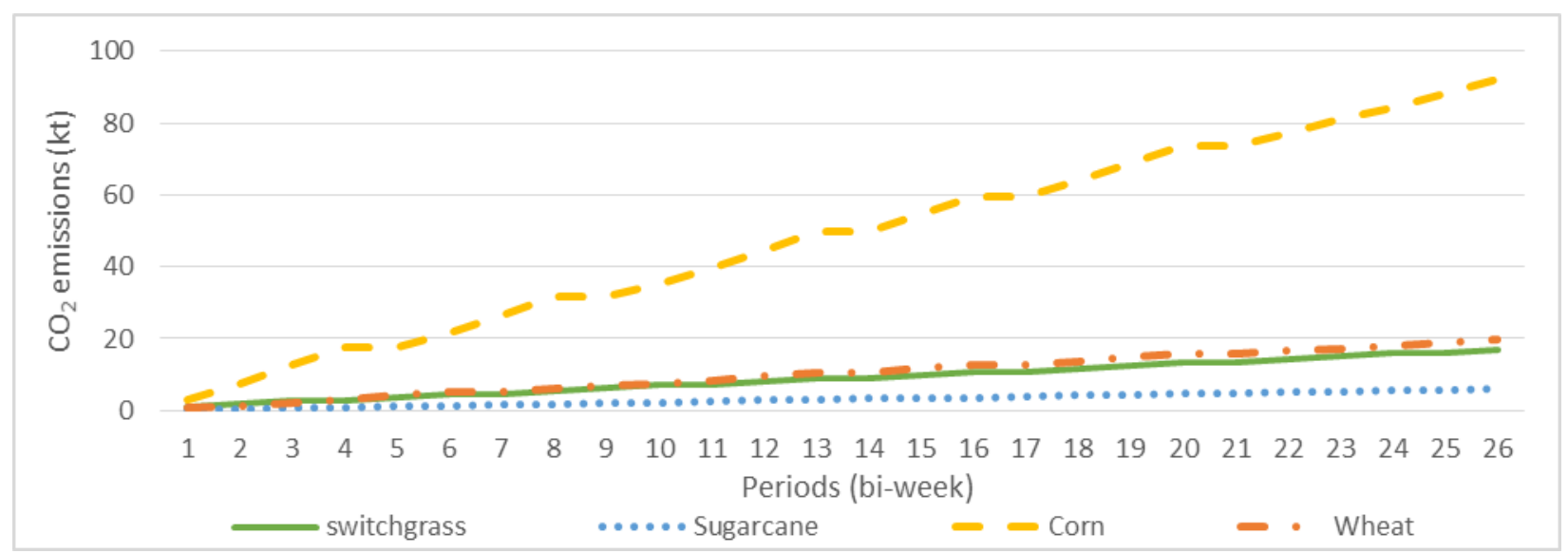

Figure 11. Cumulative emission release for only one type of biomass production during each production period 


\subsection{Impact of $\mathrm{CO}_{2}$ Cap on Results}

This experiment shows the impact of a low- and high- $\mathrm{CO}_{2}$ emissions cap on total cost. A low (high) $\mathrm{CO}_{2}$ cap is determined as 50 percent $(150 \%)$ of the base cap. As can be seen in Figure 12(a), under the low- $\mathrm{CO}_{2}$ emissions cap case, the total $\mathrm{CO}_{2}$ tax penalty increases from 1.03 percent $(\$ 704.40 \mathrm{~K})$ to 1.19 percent $(\$ 813.11 \mathrm{~K})$. On the other hand, under a high- $\mathrm{CO}_{2}$ emissions cap, the $\mathrm{CO}_{2}$ tax penalty decreases from 1.03 percent $(\$ 704.40 \mathrm{~K})$ to 0.00 percent $(\$ 0.00 \mathrm{~K})$, as shown in Figure $12(\mathrm{~b})$. However, by decreasing and increasing the cap by 50 percent, any significant changes in the biomass priorities of the model are not observed.
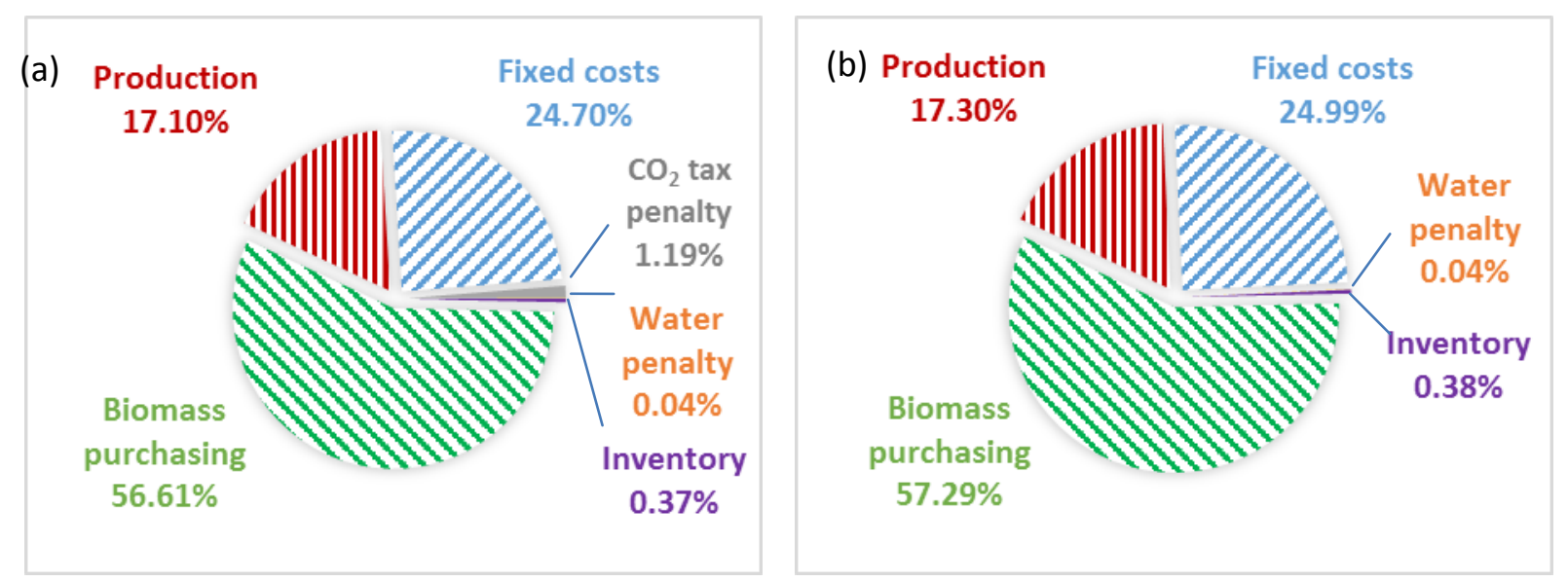

Figure 12. Breakdown of total production cost for low- $\mathrm{CO}_{2}$ emissions cap (a) and high $\mathrm{CO}_{2}$ emissions cap (b)

In order to observe the impact of the $\mathrm{CO}_{2}$ emissions penalty on biomass preferences, five different additional cases are studied, whereby the $\mathrm{CO}_{2}$ emissions tax penalty is increased by $2,4,8,16$, and 32 times (Figure 13). In cases where the $\mathrm{CO}_{2}$ emissions tax penalty is increased by 2 and 4 times, the model slowly decreases the use of sugarcane while increasing the use of switchgrass. When the $\mathrm{CO}_{2}$ emissions tax penalty is increased by 8 times, it can be seen that corn is no longer used due to its high $\mathrm{CO}_{2}$ emissions. In the case where the $\mathrm{CO}_{2}$ emissions tax penalty is increased by 16 times, biofuel production slightly shifts from switchgrass to sugarcane because sugarcane-based production releases less $\mathrm{CO}_{2}$ emissions than switchgrass-based production. When the penalty is further increased by 32 times, 
results do not change. Although, wheat has the second highest $\mathrm{CO}_{2}$ emissions, it is still utilized as the highest biomass source due to its low variable and fixed production costs.

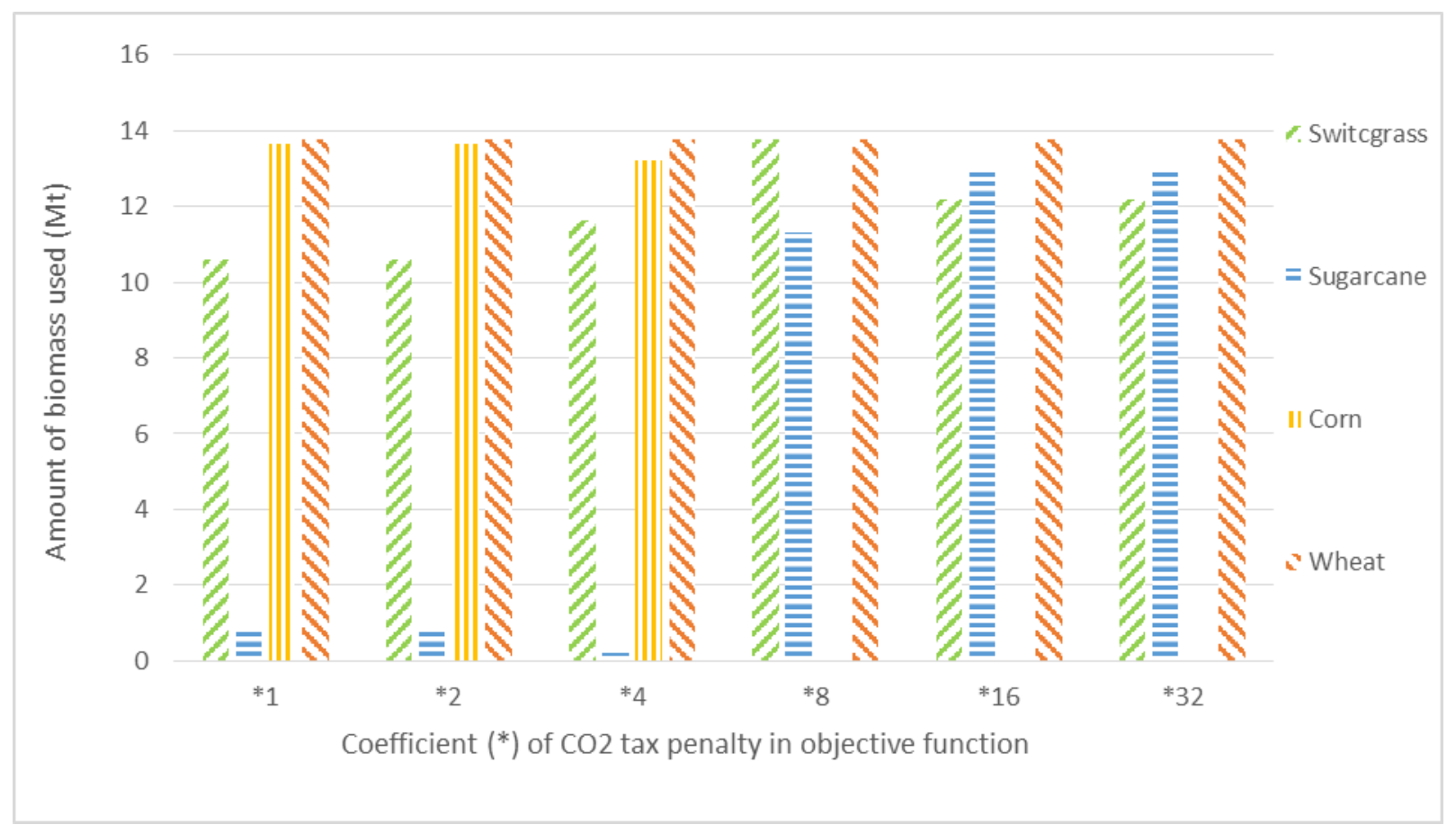

Figure 13. Impact of $\mathrm{CO}_{2}$ tax penalty on biomass preferences

\subsection{Impact of Water Usage Cap on Results}

In this experiment, the impact of low- and high-water caps on total cost and production preferences is studied. The low (high) water usage cap is determined as 50 percent $(150 \%)$ of the base cap. In the low-water usage cap case, most of the production preferences stay the same, compared to the base case. The only substantial difference found is the increase in the total water usage penalty from 0.04 percent $(\$ 24.08 \mathrm{~K})$ to 0.44 percent $(\$ 299 \mathrm{~K})$. Similarly, in the high-water usage cap case, again most of the production preferences stays the same, including most of the cost breakdown, while the water-usage penalty decreases from 0.04 percent $(\$ 24.08 \mathrm{~K})$ to 0.00 percent $(\$ 0.00)$.

Five more experimental cases for water usage, whereby the water penalty is increased by $2,4,8$, 16, and 32 times, are also considered. In any of these cases, a change in the biomass preferences is not observed. This result implies that water penalty does not play a significant role in biomass preferences of 
the model because the associated penalty values are too small compared to other costs of ethanol production.

\subsection{Impact of Technology Improvement on Results}

Ongoing research on improving the efficiency of biofuel production has motivated the study of possible impacts of technology improvement on total cost, water usage, $\mathrm{CO}_{2}$ emissions, and biomass purchasing costs. In order to study the possible effects of technology improvement, four different cases are designed, each increasing the biomass-to-biofuel conversion factor by 5 percent, 10 percent, 15 percent, and 20 percent at the beginning of the planning horizon.

Results show that each improvement in the conversion factor decreases the total cost, amount of biomass used, total biomass purchasing costs, and $\mathrm{CO}_{2}$ emissions (Figure 14). When compared with the base case, improvement amounts of 5 percent, 10 percent, 15 percent, and 20 percent in the conversion rate leads to a cost savings of 6.05 percent $(\$ 2.81 \mathrm{M}), 11.54$ percent $(\$ 5.37 \mathrm{M}), 16.45$ percent $(\$ 7.65 \mathrm{M})$, and 20.97 percent $(\$ 9.76 \mathrm{M})$, respectively. Furthermore, the 5 percent, 10 percent, 15 percent, and 20 percent technology-improvement cases increase the total tax penalty of $\$ 704.40 \mathrm{~K}$ in the base case by 3.56 percent $(\$ 20.09 \mathrm{~K}), 8.05$ percent $(\$ 56.69 \mathrm{~K}), 12.24$ percent $(\$ 86.22 \mathrm{~K})$, and 15.40 percent $(\$ 108.47 \mathrm{~K})$, respectively. Interestingly, as technology for biofuel conversion increases, the $\mathrm{CO}_{2}$ emissions tax penalties increase because the conversion rate of 5 percent or above allows the model to use more financially advantageous biomass types such as wheat and corn. Similar to $\mathrm{CO}_{2}$ emissions, in the 5 percent, 10 percent, 15 percent, and 20 percent cases, the base-case water-usage penalty (24.08K) increases to $\$ 34.02 \mathrm{~K}, \$ 42.12, \$ 41.24 \mathrm{~K}$, and $39.34 \mathrm{~K}$, respectively. In the case of 20 percent improvement, the water-usage penalty decreases in comparison to other technology improvement cases because the model decreases the use of switchgrass. From these results, it can be seen that technology improvement is critical for the efficient utilization of limited feedstock supply and reducing costs. Improving efficiency allows the manufacturer to be less dependent on different kinds of biomasses. However, in order to encourage the use of more $\mathrm{CO}_{2}$ emissions-friendly biomass sources such as switchgrass and sugarcane for ethanol production, technology improvement research should focus on these energy crops. 


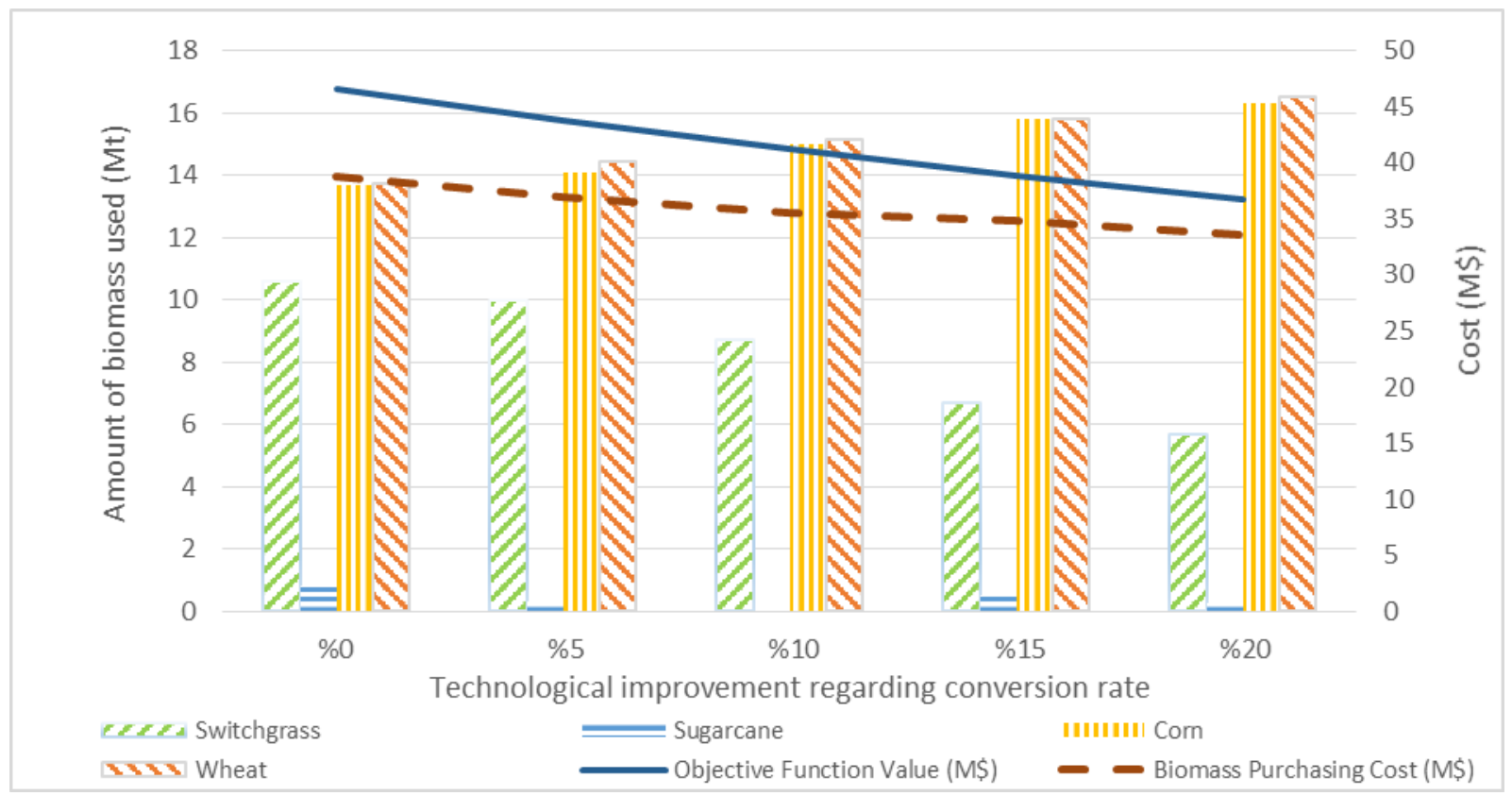

Figure 14: Computational results of technology improvement 


\section{CHAPTER 6}

\section{CONCLUDING REMARKS AND FUTURE DIRECTIONS}

In this study, an MILP lot-sizing model that defines the optimal design of ethanol production from different biomass sources is introduced. The objective of this model is to minimize total cost as well as total negative environmental impacts such as excessive $\mathrm{CO}_{2}$ emissions and water usage. To our knowledge, this study is the first to provide an MILP lot-sizing model that considers both economic and environmental impacts of ethanol production. The proposed model is applied to a real case study of a biofuel production site in Hugoton, Kansas, using four different biomass sources-switchgrass, sugarcane, corn, and wheat. As can be seen from the base case results, with current market prices, wheat, corn, and switchgrass are the most profitable sources for ethanol production. Furthermore, in the base case, due to its low conversion factor, sugarcane is less preferred for production compared to other biomass sources. Results also indicate that the model minimizes total costs by avoiding fixed costs as much as possible. This result implies that if biomass availability and production capacity constraints are met, then ethanol production using only one biomass type is preferred in order to avoid additional production setup (fixed) costs.

Different instances are investigated for understanding the impact of demand, emissions, and water cap, as well as penalties, biomass availability, and technology improvement on the model outcomes. Results indicate that the increase in demand significantly affects total costs because high demand leads to high consumption of biomass, thus necessitating the use of different biomass sources, which result in additional setup costs. The impact of emissions and a water cap has also been taken into account. Related results show that the tightness of emissions and the water cap affects the total cost but not the biomass preferences because the cost of production is significantly larger than the cost of the emissions tax and excessive water-usage penalties. Furthermore, it can be observed that biomass shortages increase the total cost significantly because preferred biomass types are depleted, and thus the model is forced to use lesspreferred biomass types. Moreover, in the case of unlimited biomass availability, switchgrass is chosen as 
the one and only biomass type for ethanol production to prevent the impact of multiple setup costs. Specifically, switchgrass is preferred because of its low production costs and high conversion rate, which offset the associated high fixed costs. If demand increases excessively, under limited biomass availability, the model prefers wheat, corn, switchgrass, and sugarcane, respectively. Finally, the impact of technology improvement is studied to understand possible outcomes of current scientific research on biomass conversion to ethanol and technology investments. Experiments show that improvements in biomass-tobiofuel conversion efficiency decrease the total cost of production and biomass purchasing costs because more efficient conversation rates enable demand to be satisfied with a lower biomass and fewer production processes. Additionally, possible conversion-efficiency improvements will allow singlebiomass-based ethanol production to be more practical and profitable in regions where biomass shortages exist.

As the $\mathrm{CO}_{2}$ emission penalty is increased, the model starts to avoid using $\mathrm{CO}_{2}$-inefficient biomass types such as corn. This result confirms the importance of government policies on controlling $\mathrm{CO}_{2}$ emissions released in the biofuel industry. Current government policies promote the production of biofuels by rewarding each gallon produced. However, in order to ensure the sustainability of biofuel production, a tax penalty could also be imposed based on the amount of $\mathrm{CO}_{2}$ emissions released from ethanol production. Apart from the $\mathrm{CO}_{2}$ emissions, water usage is also an important issue. In this study, only the water footprint in terms of water usage during the ethanol conversion phase is considered. In the future, the water footprint impact could be extended to include the total amount of water used for irrigation during crop production at the farm level in order to more realistically analyze the water-usage efficiency of different biomass types.

Future research could incorporate the impact of additional available biomass types such as miscanthus and short-rotation coppice, in order to observe the competition between different types of biomass sources. Furthermore, this model can be applied to different regions around the world while considering various biomass types and availabilities. In addition, uncertainties can be incorporated into the model since demand, price of biomass types, and biomass availability can change over time due to 
fluctuations in weather and the economic market. In this paper, the uncertainty of some parameters is handled by conducting sensitivity analyses. However, stochastic optimization techniques could be utilized in order to directly incorporate uncertainty into the model. Future research could also investigate cuttingplane approaches for solving higher-dimensional applications of the proposed MILP model. 
BIBLIOGRAPHY 


\section{BIBLIOGRAPHY}

Abengoa Bioenergy. (2011). 2 G Hugoton Project. Retrieved from Abengoa Bioeenrgy: http://www.abengoabioenergy.com/web/en/2g_hugoton_project/ [cited April 28, 2014].

Absi, N., Dauzere-Peres, S., Kedad-Sidhoum, S., Pernz, B., \& Rapine, C. (2013). Lot sizing with carbon emission constraints. European Journal of Operational Research, 227(1), 55-61.

Aden, A. (2007). Water usage for current and future ethanol production. Southwest Hydrology, 6(5), 2223.

Akgul, O., Shah, N., \& Papageorgiou, L. (2012). Economic optimisation of a UK advanced biofuel supply chain. Biomass and Bioenergy, 41, 57-72.

Bain, R. (2007). Worldwide biomass potential: Technology characterizations. Golden, CO.: National Renewable Energy Laboratory (NREL).

Benjaafar, S., Li, Y., \& Daskin, M. (2013). Carbon footprint and the management of supply chains: Insights from simple models. IIEE Transactions on Automation Science and Engineering, 1(10), 99-116.

Bernardi, A., Giarola, S., \& Bezzo, F. (2012). Optimizing the economics and the carbon and water footprints of bioethanol supply chains. Biofpr, 6(6) 656-672.

California Environmental Protection Agency Air Resources Board. (2009). Detailed California-modified GREET pathway for Brazilian sugar cane ethanol. CA: Stationary Source Division.

City of Lawrence, Kansas. (2013, August 2013). Utility Billing. Retrieved from Water and Service Rates: http://www.lawrenceks.org/utility_billing/rates [cited september 16, 2014].

Cobuloglu, H. I., \& Büyüktahtakın, İ. E. (2014). A mixed-integer optimization model for the economic and environmental analysis of biomass production. Biomass and Bioenergy, 67, 8-23.

Corsano, G., Fumero, Y., \& Montagna, J. (2013). A Mixed-integer linear programming approach for simultaneous ethanol supply chain and involved plants design considering production scheduling. Chemical Engineering, 32, 1159-1164.

Corsano, G., Vecchietti, A. R., \& Montagna, J. M. (2011). Optimal design for sustainable bioethanol supply chain considering detailed plant performance model. Computers \& Chemical Engineering, 35(38) 1384-1398.

Čuček, L., Klemeš, J. J., \& Kravanja, Z. 2012). Carbon and nitrogen trade-offs in biomass energy production. Clean Technologies and Environmental Policy, 14(3) 389-397.

Da Silva, A., Silva Marins, F., \& Barra Montevechi, J. (2013). Multi-choice mixed integer goal programming optimization for real problems in a sugar and ethanol milling company. Applied Mathematical Modelling, 37(9), 6146-6162.

Dai, D. M. (2012). Integrating carbon footprint into coordination of constant pricing and lot sizing problem. Advanced Materials Research, 518/523, 3959-3967. 
BIBLIOGRAPHY (continued)

Dominguez-Faus, R., Powers, S. E., Burken, J. G., \& Alvarez, P. J. (2009, September 18). The water footprint of biofuels: A drink or drive issue? Environmental Science \& Technology, 3005-3010. Retrieved from ScienceDaily: http://www.sciencedaily.com/releases/2009/05/090501204627.html [cited August 15, 2014].

European Renewable Energy Council. (2008). Renewable energy technology roadmap 20\% by 2020. Renewable Energy House.

Goldemberg, J., Coelho, S. T., \& Guardabassi, P. (2008). The sustainability of ethanol production from sugarcane. Energy Policy, 36(6) 2086-2097.

Gonela, V., \& Zhang, J. (2014). Design of the optimal industrial symbiosis system to improve bioethanol production. Journal of Cleaner Production, 64, 513-534.

Hammond, G. P., \& Seth, S. M. (2013). Carbon and environmental footprinting of global biofuel production. Applied Energy,112, 547-559.

Hartman, J. C., Büyüktahtakın, İ. E., \& Smith, J. C. 2010). Dynamic-programming-based inequalities for the capacitated lot-sizing problem. IIE Transactions, 42(12), 915-930.

Helmrich, M., Jans, R., Heuvel, W., \& Wagelmans , A. (2011). The economic lot-sizing problem with an emission constraint. 2nd International Workshop on Lot Sizing 2011. Istanbul.

Huang, Y., Chen, C.-W., \& Fan, Y. (2010). Multistage optimization of the supply chains of biofuels. Transportation Research Part E: Logistics and Transportation Review, 46(6), 820-830.

IBM ILOG. (2012). CPLEX 12.5 User Manual.

Kment, R. (2014, September 11). DTN Daily Ethanol Comments. Retrieved from The Progressive Farmer:

http://www.dtnprogressivefarmer.com/dtnag/common/link.do;jsessionid=F40D463483DE9231C69EB382 24F83293.agfreejvm1?symbolicName=/free/news/template1\&product=/ag/news/ethanol/commentary\&ve ndorReference $=0702 \mathrm{BB} 21 \&$ paneContentId=35\&paneParentId $=0$ [cited May 15, 2014].

Levelton Engineering Ltd. (2000). Assesment of net emissions of greenhouse gases from ethanol-blended gasolines in Canada:Lignoceluolisic feedstocks. Richmond: Agriculture and Agri-Food Canada.

Maley, S. (2012). Post-Mortem for the Ethanol Tax Credit. Retrieved from http://www.redstate.com/vladimir/2012/05/05/post-mortem-for-the-ethanol-tax-credit/.

Marvin, A. W., Schmidt, L. D., Tiffany, D. G., Benjafaar, S., \& Daoutidis, P. (2012). Economic optimization of a lignocellulosic biomass-to-ethanol supply chain. Chemical Engineering Science, 67(1) 68-79.

McAloon, A., Taylor, F., \& Yee, W. (2000). Determining the cost of producing ethanol from corn starch and lignocellulosic feedstocks. National Renewable Energy Laboratory Report. 
BIBLIOGRAPHY (continued)

National Association of Manufacturers. (2009). Economic outcomes of a U.S. carbon tax. Washington, DC: NERA Economic Consulting.

Ren, J., Manzardo, A., Toniolo, S., Scipioni, A., Tan, S., Dong, L., \& Gao, S. (2013). Design and modeling of sustainable bioethanol supply chain by minimizing the total ecological footprint in life cycle perspective. Bioresource Technology, 146, 771-774.

Ross, E. (2011). Kansas' ethanol production likely down. Wichita, Kansas: The Wichita Eagle.

Saunders, J., Izydorczyk, M., \& Levin, D. B. (2011). Limitations and Challenges for Wheat-Based Bioethanol Production. Economic Effects of Biofuel Production, Dr Marco Aurelio Dos Santos Bernardes (Ed), Canada.

Schmer, M. R., Vogel, K. P., Mitchell, R. B., \& Perrin, R. K (2008). Net energy of cellulosic ethanol from switchgrass. Proceedings of the National Academy of Sciences, 105(2), 464-469.

Shalaby, E. A. (2013). Biofuel: sources, extraction and determination, liquid, gaseous and solid biofuels conversion techniques. Cairo, Egypt: University of Ruyku.

Tan, R. R., Ballacillo, J.-A. B., Aviso, K. B., \& Culaba, A. B. (2009). A fuzzy multiple-objective approach to the optimization of bioenergy system footprints. Chemical Engineering Research and Design, 87(9), 1162-1170.

United States Department of Agriculture. (2006). The Economic Feasibilty of Ethanol Production from Sugar in the United States.

United States Department of Energy. (2012). Alternative Fuels Data Center. Retrieved from Energy Efficiency \& Renewable Energy: http://www.afdc.energy.gov/fuels/fuel_comparison_chart.pdf [cited September 13, 2014].

United States Environmental Protection Agency. (2007, April 23). Combined Heat and Power Partnership. Retrieved from United States Environmental Protection Agency: http://www.epa.gov/chp/markets/ethanol_fs.html [cited September 15, 2014].

United States Environmental Protection Agency. (2014, August 24). National Center for Environmental Economics. Retrieved from http://yosemite.epa.gov/ee/epa/eed.nsf/pages/Biofuels.html [cited September 26, 2014].

University of Kentucky. (2013). Switchgrass for Bioenergy. UK Cooperative Extension Service, 1-5.

Worldwatch Institute. (2013). Biofuels Make a Comeback Despite Tough Economy. Washington, DC: Worldwatch Institute.

Xie, F., Huang, Y., \& Eksioglu, S. (2014). Integrating multimodal transport into cellulosic biofuel supply chain design under feedstock seasonality with a case study based on California. Bioresource Technology, $152,15-23$. 